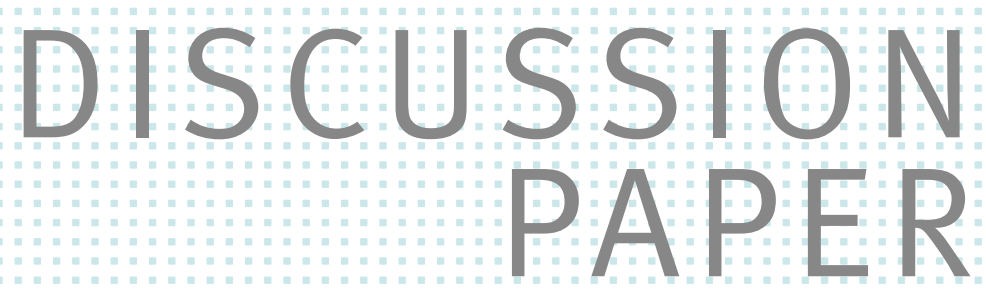

// KATHRINE VON GRAEVENITZ AND ELISA ROTTNER

Energy Use Patterns in German Manufacturing since 2003 


\title{
Energy Use Patterns in German Manufacturing since 2003
}

\author{
Kathrine von Graevenitz*and Elisa Rottner ${ }^{\dagger}$
}

February 20, 2020

\begin{abstract}
The manufacturing sector accounts for a substantial share of German GDP, employment and carbon emissions. Therefore, the manufacturing sector's energy use and carbon emissions are of crucial importance for reaching Germany's climate goals. In this paper, we analyse energy use patterns in German manufacturing between 2003 and 2014, using rich administrative micro-data. We find that although the manufacturing sector has been faced with rising energy costs as a share of total costs, energy use has not declined except briefly during the economic crisis. We also find that energy intensity in the manufacturing sector has not decreased substantially. In contrast, carbon intensity has fallen slightly between 2003 and 2014 . This can be attributed to changes in the fuel mix.
\end{abstract}

Keywords: Energy use, Fuel mix, Energy intensity, Carbon emissions, Manufacturing

JEL-Classification: D22, L60, Q41

*ZEW - Leibniz Centre for European Economic Research, P.O. Box 1034 43, 68034 Mannheim, Germany, Email: vongraevenitz@zew.de.

†ZEW - Leibniz Centre for European Economic Research and University of Basel, P.O. Box 1034 43, 68034 Mannheim, Germany, Email: rottner@zew.de. 


\section{Introduction}

The transition away from fossil and to some extent nuclear fuels began in the late 1990s in Germany. A large number of different policy measures were introduced over the years starting with the introduction of ecotaxes in 1999. Further policy instruments were introduced to incentivize the expansion of renewable electricity generation (e.g. feedin-tariffs for solar and wind energy financed through the associated Renewable Energy Surcharge on electricity introduced in 2003). In 2005, the EU emissions trading scheme was established regulating carbon emissions for certain sectors across the EU. In addition, the nuclear phaseout initiated in 2000 and reinvigorated after the Fukushima disaster in 2011 has changed the energy landscape in Germany. All these policy measures have increased the cost of electricity.

The introduction of these policy measures have spurred intense debate on what the cost in terms of loss of competitiveness and ultimately increasing unemployment may be. This is particularly the case as climate policy remains a largely national affair with many unregulated regions around the world. The German economy still depends heavily on the export-oriented manufacturing sector which accounted for $17 \%$ of employment and $25 \%$ of GDP in 2018. Due to concerns about competitiveness, several policy measures feature exemptions for particularly energy-intensive and/or trade-exposed sectors. For example, generous feed-in-tariffs have contributed to the expansion of renewable electricity generation driving down electricity costs on the wholesale market. As a result, the Renewable Energy Surcharge increased dramatically and policy makers responded by exempting more plants from paying the full surcharge from 2012 onwards.

This paper takes stock of the energy use patterns and trends in the manufacturing sector from 2003 to 2014. Manufacturing accounted for 30\% of final energy demand and $40 \%$ of electricity use in 2018. We examine the evolution of fuel use, energy intensity and carbon emissions using the most detailed administrative data available. Our findings are sobering: By and large, energy intensity in German manufacturing has remained largely unchanged over the 12 year period. Fuel switching has however contributed to bringing down carbon intensity slightly. A growing trend towards self-generation of electricity can be observed which is consistent with incentives to avoid regulation through electricity surcharges and possibly also the emissions trading scheme. Energy costs have been rising over time also in terms of their share of total costs, but primarily before 2010 . 
We conclude that German manufacturing is still far from achieving substantial emissions reductions. In consequence, more research is necessary to better understand the effectiveness of individual policy measures targeting energy efficiency and how they can be improved.

The paper is structured as follows: Section 2 describes the data available for the analysis and our data preparation. Section 3 discusses the development of energy and fuel use in manufacturing and energy and carbon intensity. Section 4 takes a closer look at energy costs at the firm level. Setion 5 examines heterogeneity within manufacturing and is followed by a short conclusion in Section 6 .

\section{Data}

\subsection{The AFiD panels}

We investigate the developments in energy use patterns in the manufacturing sector in Germany using official micro-level data from the Federal Statistical Offices of the Bund and the Länder, the so-called AFiD panels ( Amtliche Firmendaten für Deutschland": Official Firm Data for Germany). Specifically, we make use of the panels "industrial plants", "energy use" and "cost structure".

The panel "industrial plants" contains information on the number of employees per plant, sales, payroll statistics, the value of output and exports (in $€$ ) and further variables on the economic activities of plants. The AFiD panel collects this information from four individual sources: the "monthly reports on manufacturing, mining and quarrying plants", the "annual report of manufacturing, mining and quarrying plants", the "investment survey for manufacturing, mining and quarrying plants" and the "quarterly production survey for manufacturing plants". Participation in the survey is mandatory for all industrial plants in the German manufacturing sector with more than 20 employees. We have data available from 1995 to 2014.

The information from the panel "industrial plants" is combined with the panel "energy use". This data set contains information on the energy use of industrial plants, such as the consumption of different fuels, electricity procurement, or electricity self-generation. Again, all plants with more than 20 employees are required to report in the survey. Until 2002, the information on the energy use of plants was based on information from the 
"monthly report on manufacturing, mining and quarrying plants". In 2003, a separate survey on the annual energy use of manufacturing, mining and quarrying plants was introduced. Due to the creation of this stand-alone survey, information on energy use are more accurate and more detailed from 2003 onwards. Since more characteristics of energy use are available after 2002 and the modification of the reporting leads to breaks in the data (see e.g. Petrick et al. (2011) on this point), we limit our analysis to the time span from 2003 to 2014.

The "cost structure survey for the manufacturing, mining and quarrying industries" contains information at the firm level. Hence, while we analyse energy use, emissions and production variables at the plant level, we look at the firm level when investigating energy costs and total costs. The cost structure survey covers a sample of around 18,000 firms per year. Bigger firms are more likely to be sampled, and firms with more than 500 employees are fully included in the survey.

Throughout our analyses, we focus our attention on the manufacturing sector that accounted for around 25\% of GDP (DeStatis, 2019) and around $30 \%$ of carbon emissions in 2018. ${ }^{1}$ This leaves us with a panel of around 40,000 plants per year.

\subsection{Data cleaning}

While the research data centres and the statistical offices conduct various quality controls with the data. In addition, we adopt the following separate data cleaning procedure. First, we drop all observations that reported annual revenues of 0 or $1 €$ as those are implausible values. Furthermore, we exclude all observations with an annual output of below $10.000 €$.

We further exclude all observations that report a negative energetic fuel use and those observations where our calculated measure of total energy use is below zero. There are some firms in which one plant reports the energy statistics for several plants within the firm. While we can identify the firms in which one plant reports the energy data for several plants, we cannot properly allocate the fuel and electricity use across the plants and drop all plants within these firms. Finally, we drop outliers in terms of fuel use, where outliers are defined as plants where one standard deviation of fuel use within the plant is bigger than 100 times the median fuel use of the plant.

\footnotetext{
${ }^{1}$ We drop all observations in the mining and quarrying sector.
} 
Figure 1 shows the total energy use per year that we lose by conducting this data cleaning approach. Overall, between 1995 and 2014, we drop around 46,000 observations, roughly 2,300 plants per year.

\subsection{Further data sources}

The administrative micro-data from the AFiD panels constitute our main data source. We complement those data with information on emission factors. To measure a plant's carbon emissions, we convert its fuel use and electricity procurement into carbon emissions using emission factors from the German Environment Agency (Umweltbundesamt - UBA). Emission factors for fuel consumption are taken from the publication "Carbon Dioxide Emissions for the German Atmospheric Emission Reporting 1990-2014". The factors used for electricity procurement are taken from "Development of the CO2-emissions of the German electricity mix from 1990 to 2017") (Umweltbundesamt, 2016, 2018b). The exact emission factors used can be found in Table 3 in the Appendix.

Finally, we make use of the commercial producer price index from Destatis to deflate the monetary values of output (DeStatis, 2018). This is necessary when comparing the value of output over time: the value of output could have changed both because of price changes and because of changes in real output. The price index we use accounts for

the fact that developments of prices between sectors can differ. We use the commercial producer price index from Destatis at the 3-digit sector level (NACE codes).

\section{Results}

\subsection{Energy and fuel use in the German manufacturing sector}

Figure 1 depicts the development of the aggregate energy use of the manufacturing sector over time as well as the median energy use. As can be seen, energy use increased substantially between 2003 and 2014. In our cleaned data set, energy use increases from roughly 696 TWh in 2003 to around 859 TWh in 2014 which is an increase of 163 TWh, or approximately 23\%. The 2009 recession in Germany is clearly visible in the data: From 2008 to 2009, energy use decreased by more than $100 \mathrm{TWh}$ which is equivalent to a 
$13 \%$ drop as compared to the previous year. However, energy use recovered quickly and returned to pre-crisis levels already in 2010 .

In contrast, the median energy use increased only slightly from 889 MWh in 2003 to $900 \mathrm{MWh}$ in 2014 (i.e. a 1\% increase as compared to 2003). This apparently small increase comes about due to a sharp decline of $8 \%$ of the energy use of the median plant from 2013 to 2014 masking the generally increasing tendency. It is notable that the energy use of the median single plant firm follows a virtually identical pattern. However, the increase in total energy use between 2003 and 2014 is less marked for single plant firms than for all firms (only around 13\%), suggesting that the increase in total energy use is mostly driven by multiplant firms. Revenues have been increasing over the same period of time (see Figure 2).

Underlying the aggregate statistic on energy use in manufacturing is significant heterogeneity in energy use between plants within German manufacturing as depicted in Figure 3. As can be seen, the mean energy use of the German manufacturing plant is consistently higher than the 90th percentile. In other words, the distribution of energy use across plants in the German manufacturing sector is highly right-skewed with a few large users driving the mean above the 90th percentile. This is in line with the findings of Petrick et al. (2011) and has not changed over time.

As is shown in Figure 4, most of the variation in the energy use of manufacturing plants comes from variation in their fuel use: Electricity use has been pretty constant over time, even in the 2009 recession. In contrast, the use of primary fuels by plants has incrased significantly over time.

While all 41,459 plants in our sample in 2014 used electricity, gas is the most commonly used primary fuel (see Figure 5): In 2014, 28,747 plants (and hence nearly $70 \%$ of all manufacturing plants) consumed gas for energetic purposes (e.g. generating heat or electricity). ${ }^{2}$ In terms of aggregate energy use, gas was even more important than electricity with a use of 344 TWh as compared to 217 TWh for electricity. Coal constitutes the next most important fuel in terms of aggregate use (148 TWh) even though there are only few users (389). More than a third of plants use oil, but the aggregate use is less

\footnotetext{
${ }^{2}$ To the extent that fuels are used to generate electricity they are double-counted in Figures 5 and 6. We subtract the self-generated electricity in Figures 1 and 4 to accurately represent aggregate energy use without double-counting.
} 


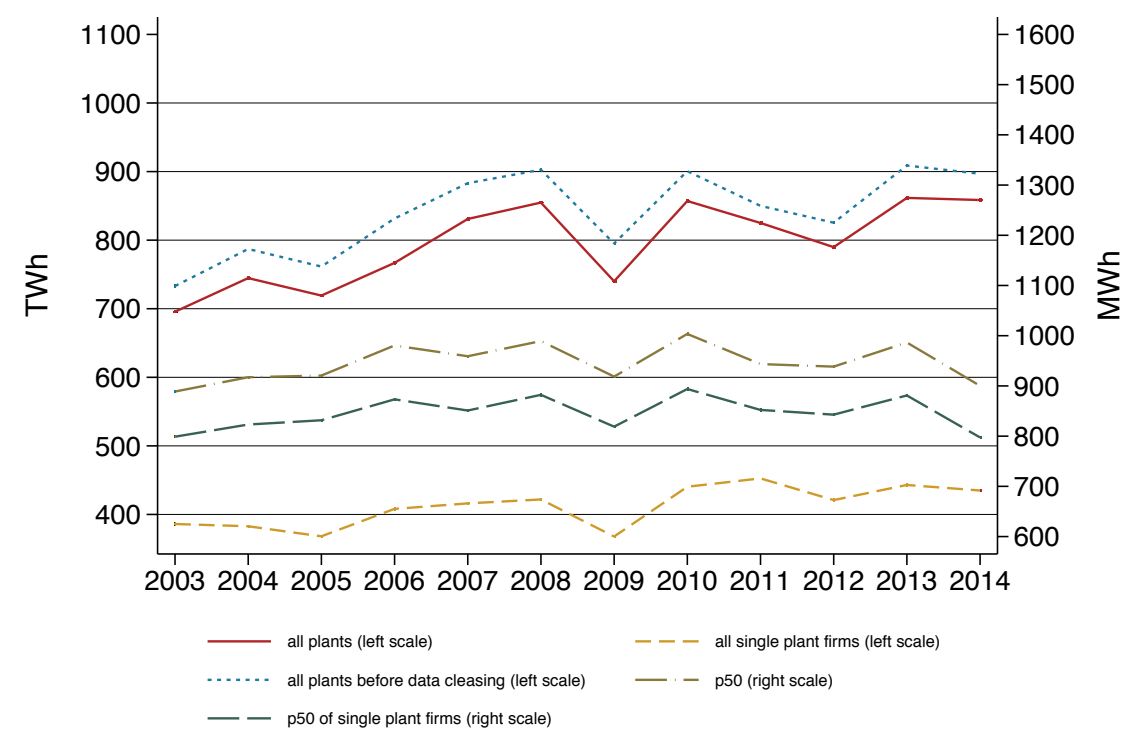

Source: DOI: 10.21242/43531.2003.00.03.1.1.0 to 10.21242/43531.2014.00.03.1.1.0. Own calculations.

Figure 1: Aggregate energy use of the whole industry sector, single plant firms, and the median (single) plant 


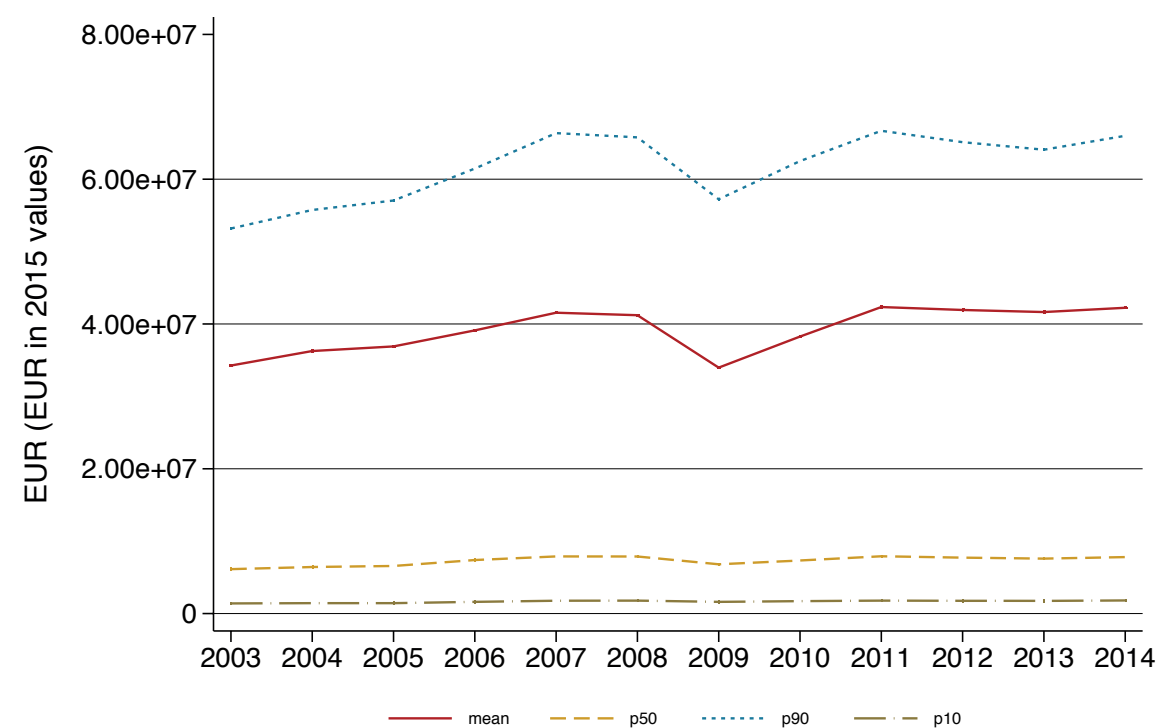

Source: DOI: 10.21242/42111.2003.00.01.1.1.0 to 10.21242/42111.2014.00.01.1.1.0. Own calculations.

Figure 2: Revenues of all plants across sectors (mean, median, top and bottom percentiles) in 2015 prices 


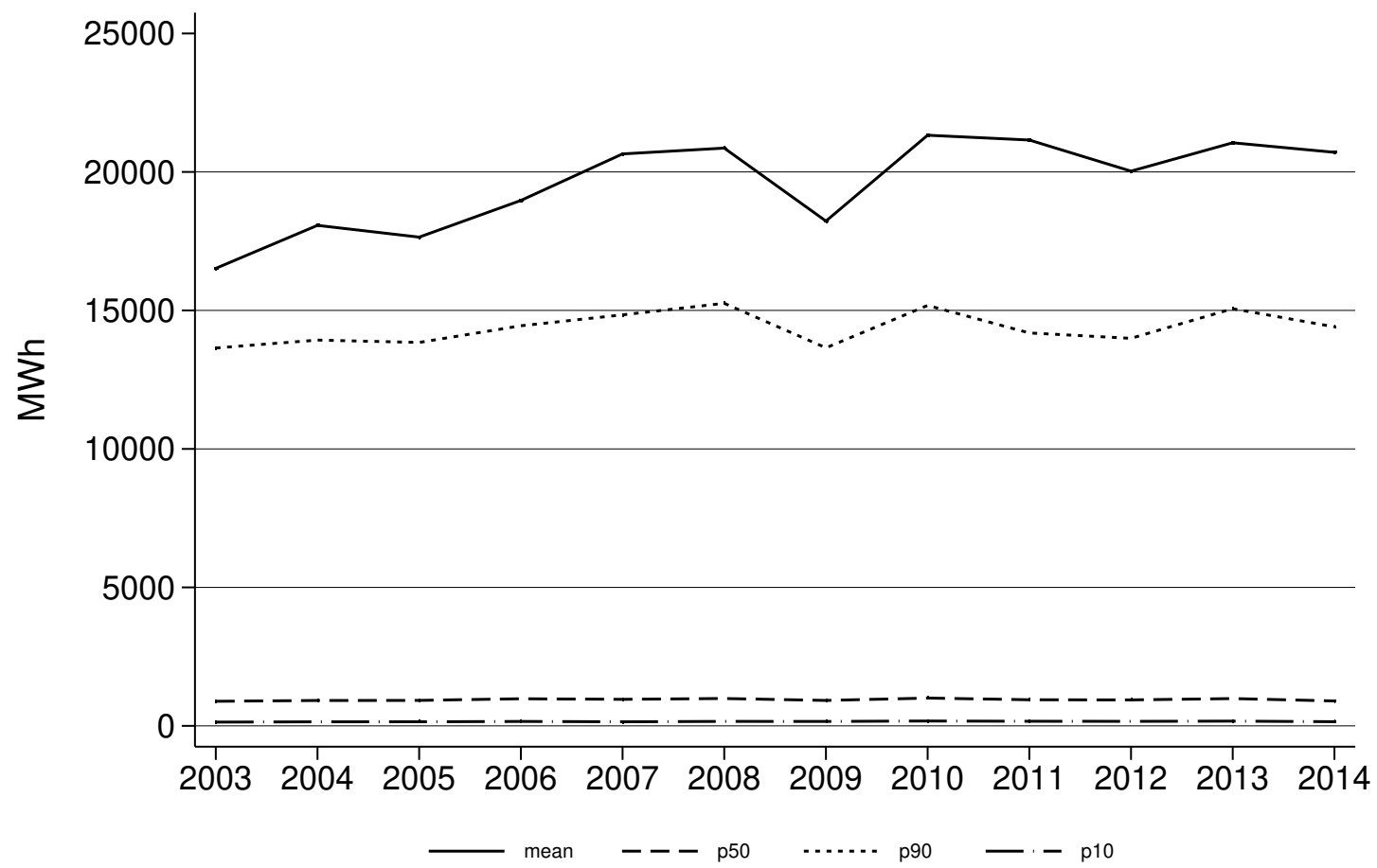

Source: DOI: 10.21242/43531.2003.00.03.1.1.0 to 10.21242/43531.2014.00.03.1.1.0. Own calculations.

Figure 3: Mean, median and dispersion of total energy use by industrial plants between 2003 and 2014 


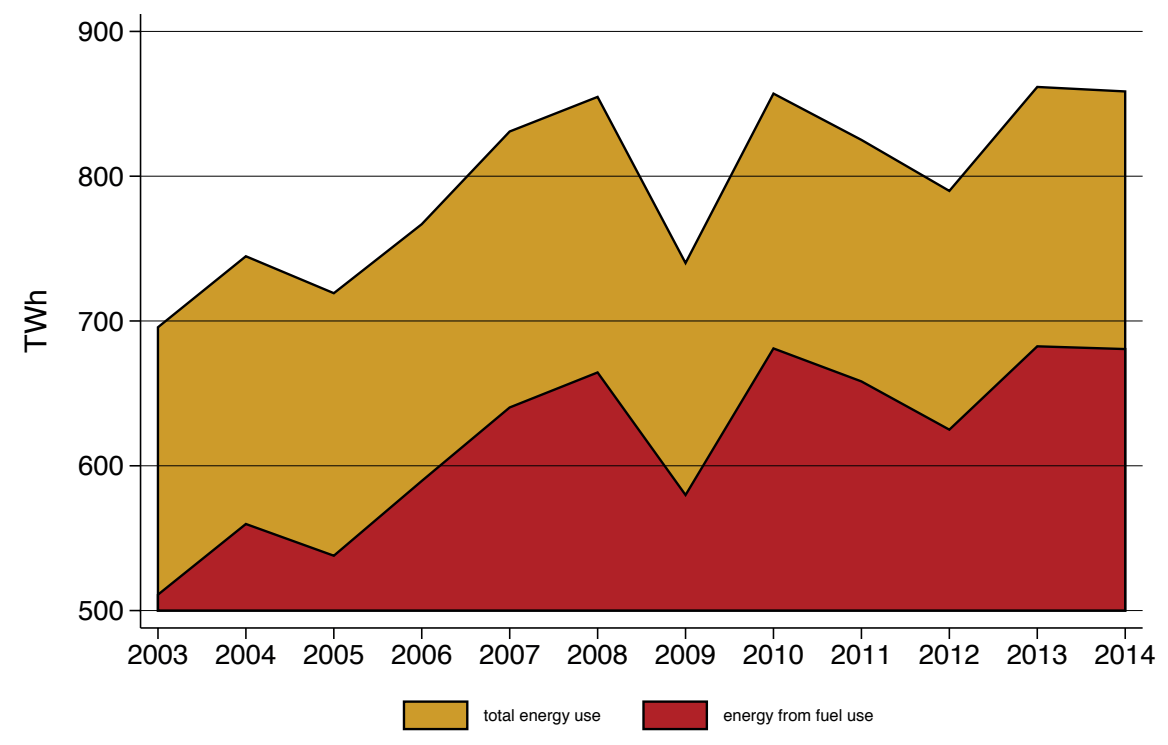

Source: DOI: 10.21242/43531.2003.00.03.1.1.0 to 10.21242/43531.2014.00.03.1.1.0. Own calculations.

Figure 4: The development of aggregate fuel use and energy use in all sectors between 2003 and 2014 
than 10 percent of total energy use at 84 TWh. Heat and renewable energy sources are less commonly used: In 2014, 3,180 plants used a total of 46 TWh of heat, whereas 1,835 plants used renewable energy sources for energetic purposes with an aggregate use of 36 TWh. $^{3}$

Figure 6 depicts the development of aggregate fuel use over time. Once again, it is visible that electricity use has remained constant over time. In contrast, the use of oil has been declining in recent years. Consumption of gas and heat have both increased. However, while gas accounts for a major share of total fuel use, heat only constitutes a minor share. It is notable that since 2007, the aggregate use of renewable energy sources has not increased substantially.

The increase in energy use and the change in the fuel mix in manufacturing over time obviously affects the overall carbon emissions. Figure 7 shows the evolution of total carbon emissions from the whole sector, taking account of both indirect emissions from electricity procurement and of direct emissions from fuel use. Total carbon emissions have increased from 2003 to 2014, following a path similar to energy use with the 2009 recession constituting a major drop in emissions. Like energy use, however, emissions almost completely rebounded to the pre-crisis level already in 2010.

Interestingly, electricity procurement and the corresponding indirect emissions follow a different pattern, as depicted in Figure 8. While the economic crisis in 2009 is also clearly visible for electricity procurement and indirect emissions, both of those variables remain below their pre-crisis levels after 2009. Since electricity consumption is relatively constant over time (Figures 4 and 6), declining electricity procurement after 2009 implies that electricity self-generation must have increased in those years. Indeed, Figure 9 shows that self-generation of electricity has become more important in the manufacturing sector: While self-generated electricity amounted to approximately 30 TWh in 2003, it equaled nearly 46 TWh in 2014, an increase of more than 50\% as compared to 2003. The share of self-generated electricity in total electricity use has increased from $14 \%$ in 2003 to $21 \%$ in 2014 as a result.

\footnotetext{
${ }^{3}$ The exact numbers on fuel users and fuel use are displayed in Table 4 in the Appendix.
} 


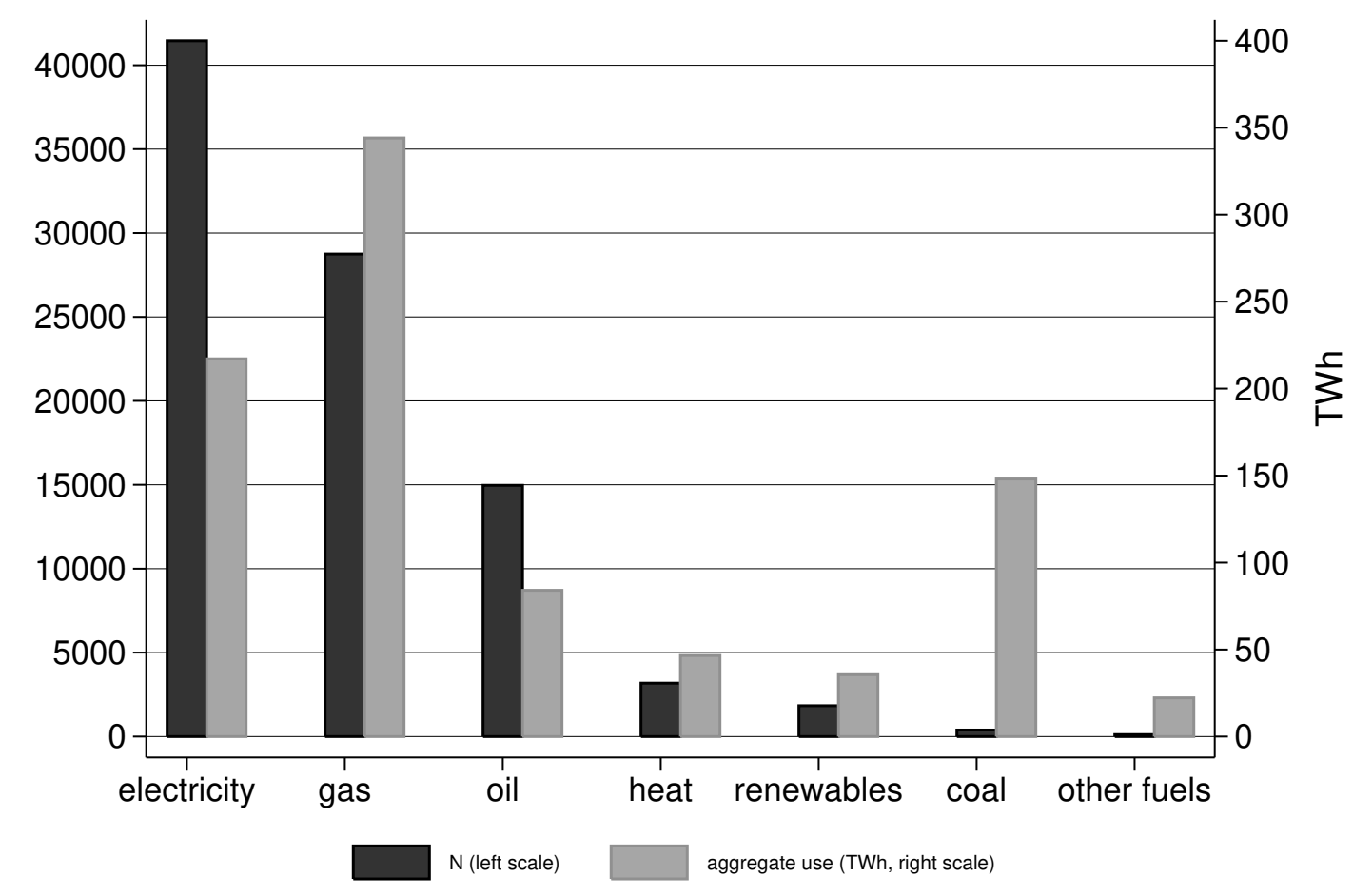

Source: DOI: $10.21242 / 43531.2003 .00 .03 .1 .1 .0$ to $10.21242 / 43531.2014 .00 .03 .1 .1 .0$. Own calculations. The exact numbers can be found in Table 4 in the Appendix.

Figure 5: Users and consumption of different fuels and electricity in all sectors in 2014 


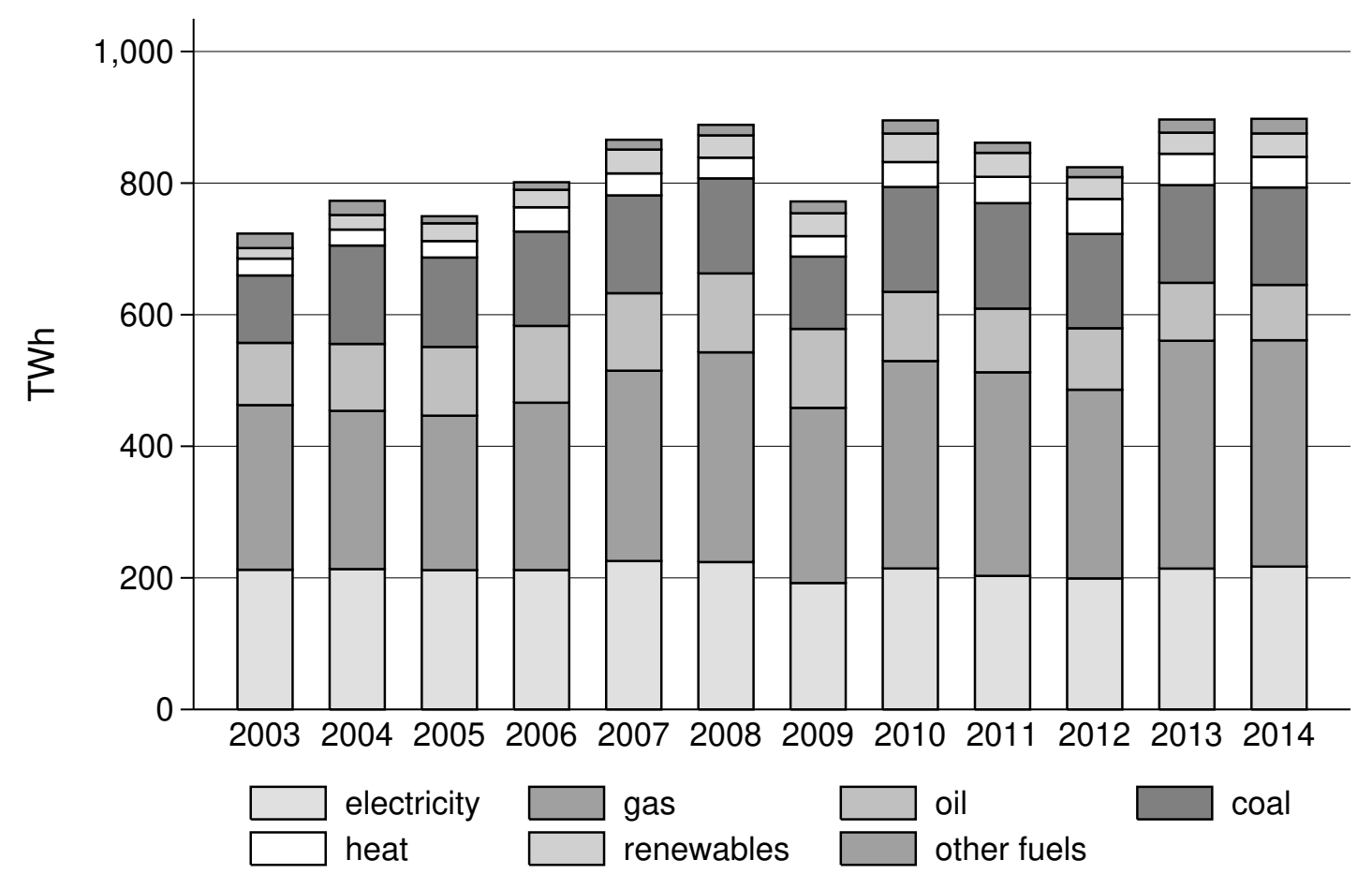

Source: DOI: $10.21242 / 43531.2003 .00 .03 .1 .1 .0$ to $10.21242 / 43531.2014 .00 .03 .1 .1 .0$. Own calculations.

Figure 6: The consumption of different fuels and electricity over time in all sectors 


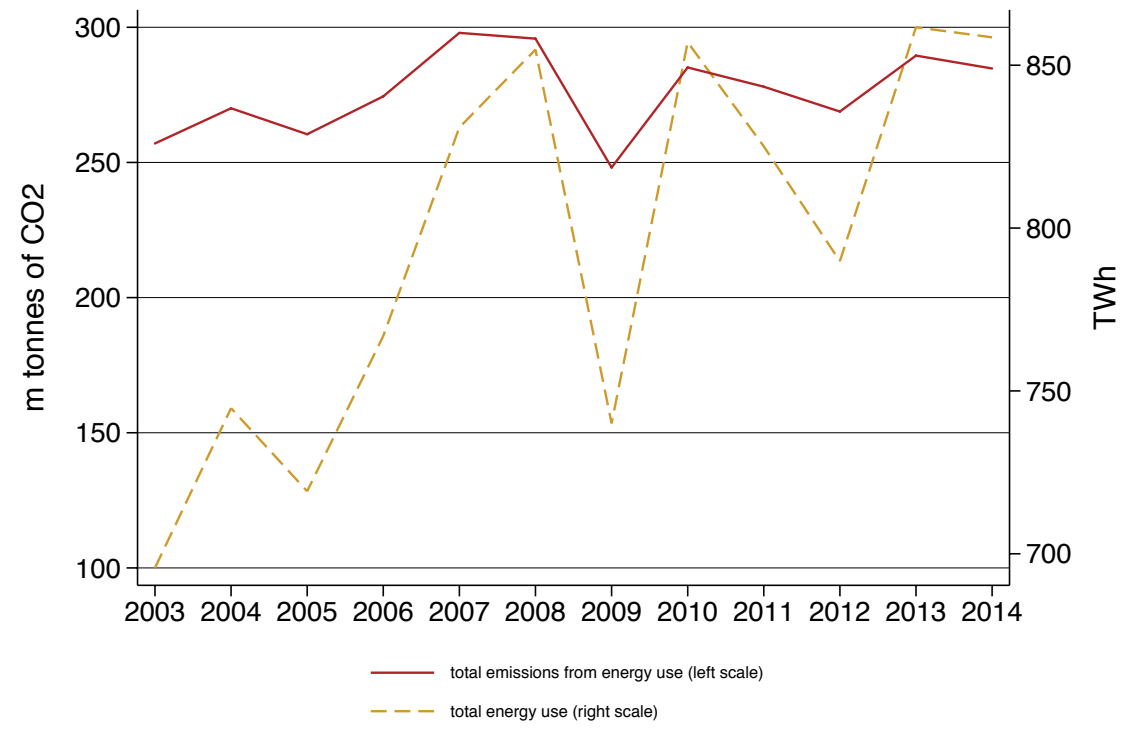

Source: DOI: 10.21242/43531.2003.00.03.1.1.0 to 10.21242/43531.2014.00.03.1.1.0. Own calculations. For information on the emission factors used for calculating the emissions, see Table 3 in the Appendix.

Figure 7: The development of total emissions from energy use and total energy use from 2003-2014 in all sectors 


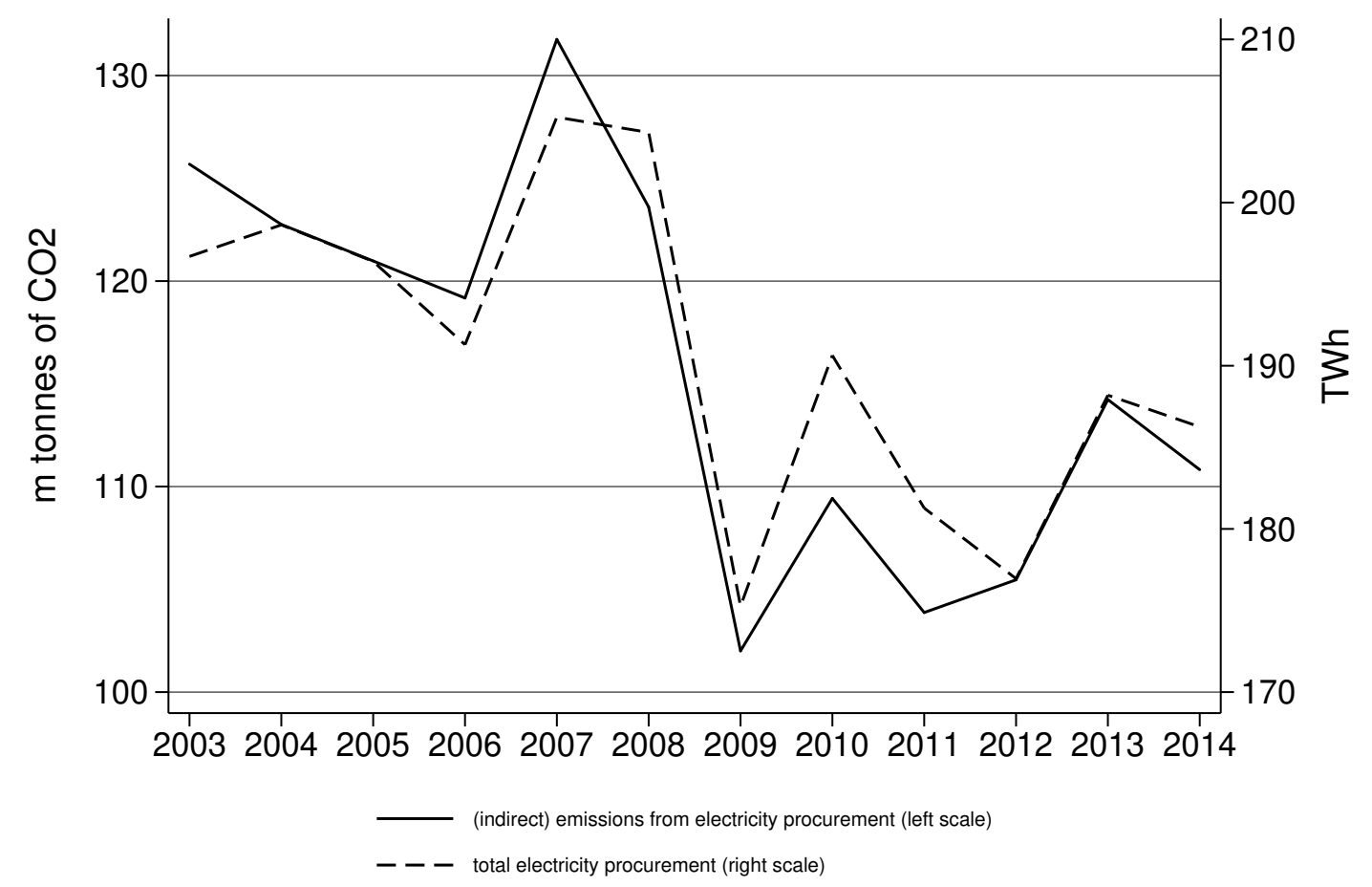

Source: DOI: 10.21242/43531.2003.00.03.1.1.0 to 10.21242/43531.2014.00.03.1.1.0. Own calculations. For information on the emission factors used for calculating the emissions, see Table 3 in the Appendix.

Figure 8: The development of (indirect) emissions from electricity procurement and total electricity procurement from 2003-2014 in all sectors 


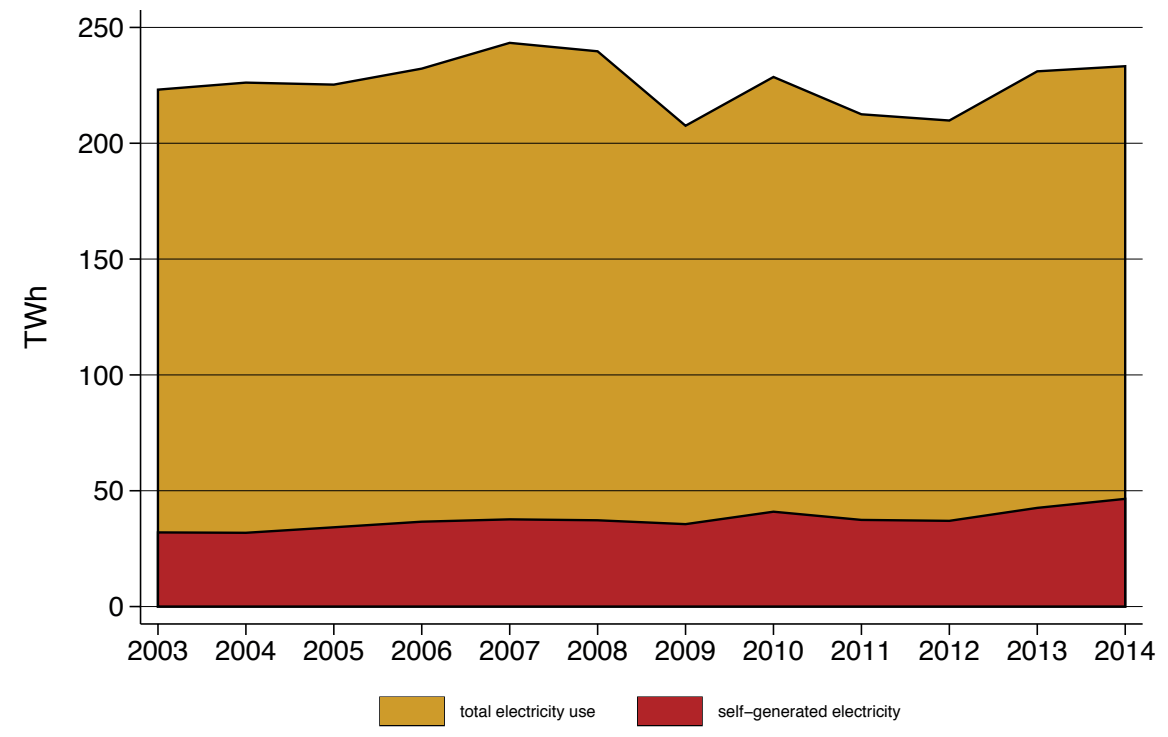

Source: DOI: 10.21242/43531.2003.00.03.1.1.0 to 10.21242/43531.2014.00.03.1.1.0. Own calculations.

Figure 9: The development of aggregate electricity use and self-generation from 2003-2014 in all sectors 


\subsection{Energy and carbon intensity}

The previous section has shown an upward trend of energy use in the German manufacturing sector. Even though total energy use has increased, energy intensity may have declined in the German manufacturing sector over the years. Petrick et al. (2011) e.g. find that between 1995 and 2006, energy intensity decreased almost monotonically: According to their results, the median plant in the manufacturing sector used $18 \mathrm{kWh}$ per $1.000 €$ of output less in 2002 as compared to 1995. However, they do not account for inflation in their analysis which implies that the decreases in energy intensity are overstated. Figure 10 depicts the development of energy intensity between 2003 and 2014, once in current prices and once in deflated prices (2015-prices). We calculate energy intensity as the ratio between total energy use (in $\mathrm{kWh}$ ) and the value of (deflated) output (in $1.000 €$ ).

The graphs show that once the price development is accounted for, there is little evidence of a decrease in energy intensity between 2003 and 2014: While it seems that there is a general declining trend in energy intensity for all plants (i.e. average and median plant, but also at the 90th percentile), those decreases are much weaker once we account for inflation. ${ }^{4}$ This is perhaps surprising given that during this period, several policies have been imposed with the goal to decrease energy use and energy intensity.

The intuition provided by the graphs is also supported by regression results reported in Table 1: We regress the logarithm of energy intensity on the year and a plant-fixed effect $\mu_{i}$, clustering standard errors on the plant level:

$$
\log (\text { energy_intensity })_{i, t}=\beta \times \text { year }_{t}+\mu_{i}+\epsilon_{i, t}
$$

If energy intensity has decreased, the coefficient $\beta$ should take on a negative value. However, using the deflated value of output to calculate energy intensity, the coefficient is close to zero and even slightly positive $(\beta=0.005)$ corresponding to an increase in intensity of 0.5 percent. Without plant-level fixed effects, energy intensity has declined

\footnotetext{
${ }^{4}$ The price deflators from DeStatis are not available for all 3-digit sectors in our sample. Therefore, the sample underlying the graph with the deflated energy intensities differs slightly from the graph that does not account for price developments. Specifically, price deflators are not available (at least for some years) in the sectors $131,133,254,256,268,301,303,304,329,331$ and 332 . We checked whether the differences in the development of energy intensities across the two graphs derives from the different samples by also displaying the development of not-deflated energy intensity excluding the sectors where no price indices are available. Results are shown in the appendix. The difference in the sample structure does not seem to be driving the results.
} 

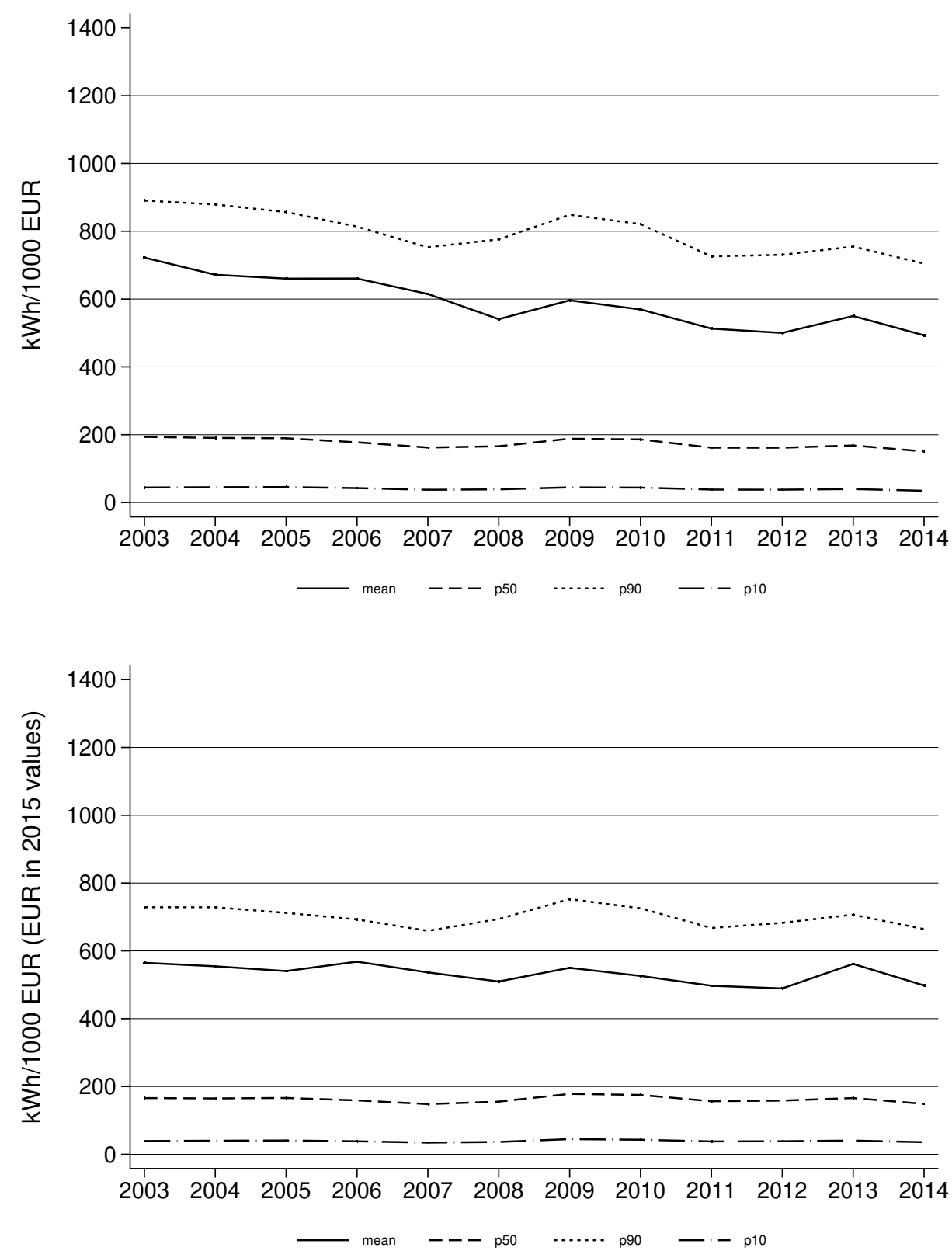

Source: DOI: $10.21242 / 43531.2003 .00 .03 .1 .1 .0$ to $10.21242 / 43531.2014 .00 .03 .1 .1 .0$. and DOI: 10.21242/42111.2003.00.01.1.1.0 to 10.21242/42111.2014.00.01.1.1.0. Own calculations. Information on price deflators are taken from DeStatis (2018).

Figure 10: Energy intensity of all plants across sectors (mean, median top and bottom percentiles) in current prices (top) and in 2015 prices (bottom) 

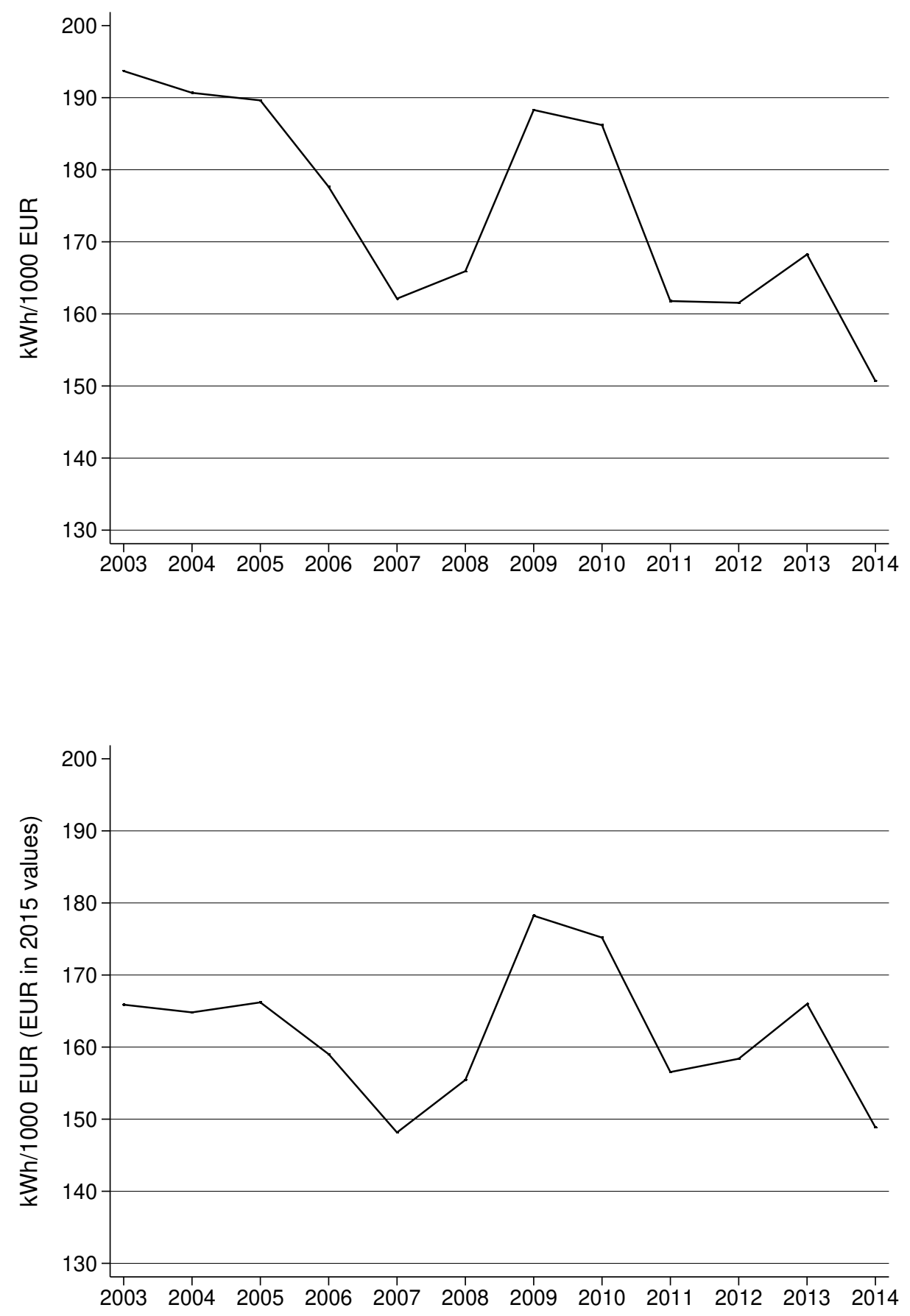

Source: DOI: $10.21242 / 43531.2003 .00 .03 .1 .1 .0$ to $10.21242 / 43531.2014 .00 .03 .1 .1 .0$. and DOI: 10.21242/42111.2003.00.01.1.1.0 to 10.21242/42111.2014.00.01.1.1.0. Own calculations. Information on price deflators are taken from DeStatis (2018)

Figure 11: Median energy intensity of all plants across sectors in current prices (top) and in 2015 prices (bottom) 
by 0.2 percent per year on average. The difference between the within-plant regression (with plant fixed effects) and the between plants regression without fixed effects suggests that the composition of the manufacturing sector has shifted slightly towards less energy intensive plants over time, whereas energy intensity within existing plants has not improved. ${ }^{5}$

The previous section described how the fuel mix of the German manufacturing sector has changed over time. Figure 12 shows that even though energy intensity in real terms has not declined substantially since 2003, fuel switching has led to a slight decrease of carbon intensity in real terms. The median of carbon intensity decreased by roughly $10 \mathrm{~kg}$ per $1,000 €$ of output; reductions in the upper tail of the distribution (i.e. in the 90th percentile) were larger in absolute terms. Rerunning the regression in equation 1 for carbon intensity yields a statistically significant and negative coefficient for $\beta$ of around -0.001, supporting that carbon intensity has decreased over time. On average, carbon intensity decreased by around 0.1 percent each year. Again the between plants regression suggest a larger effect of 0.8 percent decline in carbon intensity per year on average. ${ }^{6}$

Table 1: Regression of energy and carbon intensity on a linear time trend

\begin{tabular}{lcccc}
\hline \hline & Energy intensity & Energy intensity & Carbon intensity & Carbon intensity \\
& $(1)$ & $(2)$ & $(3)$ & $(4)$ \\
\hline year & $0.005^{* * *}$ & $-.002^{* *}$ & $-.001^{* * *}$ & $-.008^{* * *}$ \\
& $(0.0004)$ & $(0.0009)$ & $(.0004)$ & $(.0006)$ \\
\hline Plant FE & YES & NO & YES & NO \\
$N$ & 441,975 & 441,975 & 441,960 & 441,960 \\
$N_{\text {groups }}$ & 54,844 & - & 54,842 & - \\
$\mathrm{R}^{2}$ & 0.002 & 0.000 & 0.000 & 0.001 \\
\hline \hline
\end{tabular}

Notes: The regressions include observations from 2003-2014. The dependent variable is the logarithm of energy intensity (columns (1) and (2)) or carbon intensity (columns (3) and (4)). Standard errors are clustered at the plant level. p-values are in parentheses. ${ }^{*},{ }^{* *}$ and ${ }^{* * *}$ indicate significance at $10 \%, 5 \%$ and $1 \%$, respectively.

\footnotetext{
${ }^{5} \mathrm{~A}$ regression distinguishing between self-generating plants and those without own electricity generation does not change these results. The interaction of the time trend with a self-generation dummy is not statistically significant.

${ }^{6} \mathrm{~A}$ regression distinguishing between self-generating plants and those without own electricity generation does not change these results. However, the change in carbon intensity over time is significantly larger for those plants with self-generation in the between regression.
} 


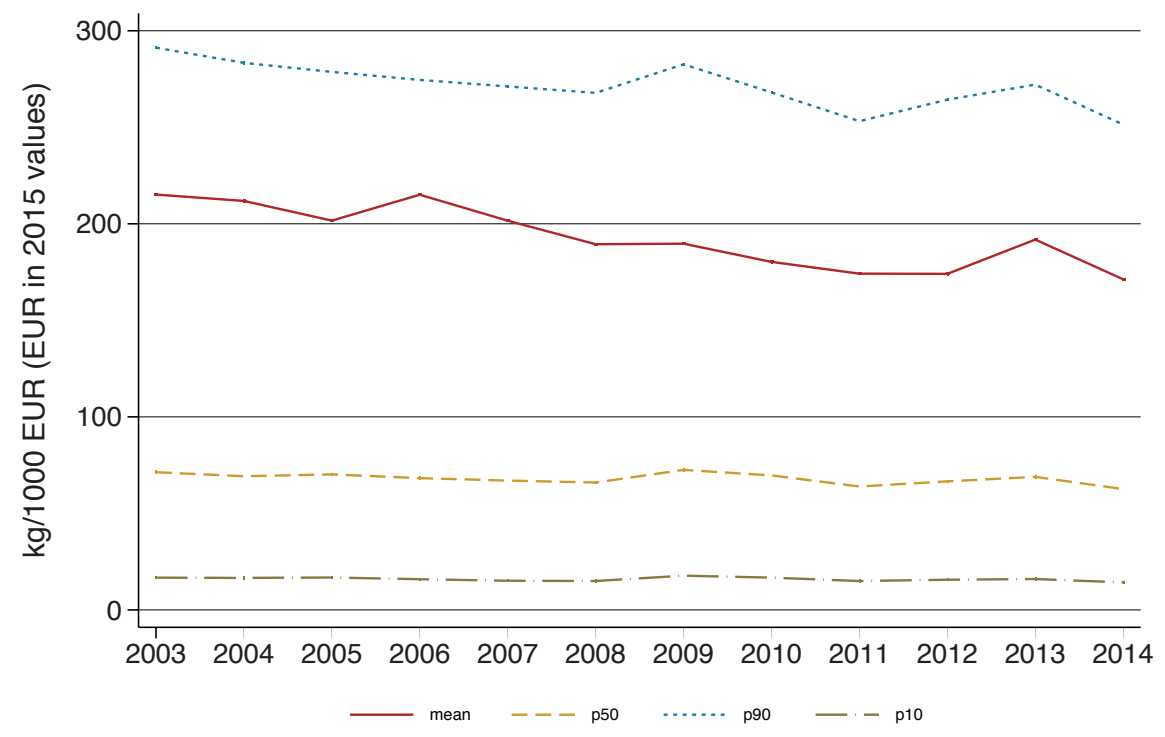

Source: DOI: $10.21242 / 43531.2003 .00 .03 .1 .1 .0$ to $10.21242 / 43531.2014 .00 .03 .1 .1 .0$. and DOI: 10.21242/42111.2003.00.01.1.1.0 to 10.21242/42111.2014.00.01.1.1.0. Own calculations. Information on price deflators are taken from DeStatis (2018).

Figure 12: Aggregate carbon intensity of all plants across sectors at 2015 prices 


\section{Energy costs in German manufacturing}

Energy is an important input factor in the production process in German manufacturing. However, the cost share of energy costs in total costs is rather small, as can be seen in Figure 13 and Figure 14 making up 2-3 percent of total costs on average. ${ }^{7}$

The costs for resources and intermediates, labour costs and costs for repair, maintenance, rent, retail and others constitute the bulk of costs in the German manufacturing sector. Still, in absolute terms, energy costs have grown substantially over the years: In 2003, the sampled firms in the manufacturing sector spent roughly 19 billion $€$ on energy. In 2014 , this number had risen to nearly 32 billion $€$ (in current, not in real prices). This $70 \%$ increase is markedly higher than the roughly 40\% increase in total costs from 1165 billion $€$ in 2003 to 1613 billion $€$ in 2014 .

Hence, energy costs did not only rise in absolute terms in the manufacturing sector, but also the share of energy costs in total costs has increased, as shown in Figure $14 .^{8}$ The average energy cost share increased by roughly 37\% between 2003 and 2014, the median even by $47 \%$ (albeit from low levels). The increases amount to $35 \%$ and $36 \%$, respectively, for the 10th and 90th percentile of the distribution. Hence, the energy cost share has not only increased for those plants for whom energy constitutes an important input factor and which already had a relatively high energy cost share in 2003, but the whole distribution is affected. This is also visible in Figure 15 that illustrates Kerneldensities of the logged energy cost share for 2007 and 2014: The distribution of cost shares shifts to the right but also becomes more compressed. The cost share for the upper percentiles of the distribution does not change. This may be explained by the existence of a variety of policy exemptions and reductions in taxes and charges for very energy and electricity intensive plants and firms.

Since energy intensity has not changed substantially over time, as discussed in the previous section, it seems likely that increases in the energy cost share are due to increases in energy and electricity prices. In fact prices for gas and oil increased substantially

\footnotetext{
${ }^{7}$ Energy costs are reported in the cost structure survey as an aggregate measure for the firm, but not the expenditure on individual fuels or electricity. Expenditures for emission allowances is not included in the energy costs.

${ }^{8}$ The developments of labour cost shares, capital cost shares and resource/intermediate inputs cost shares are shown in Figures 25, 26 and 27 in the Appendix.
} 


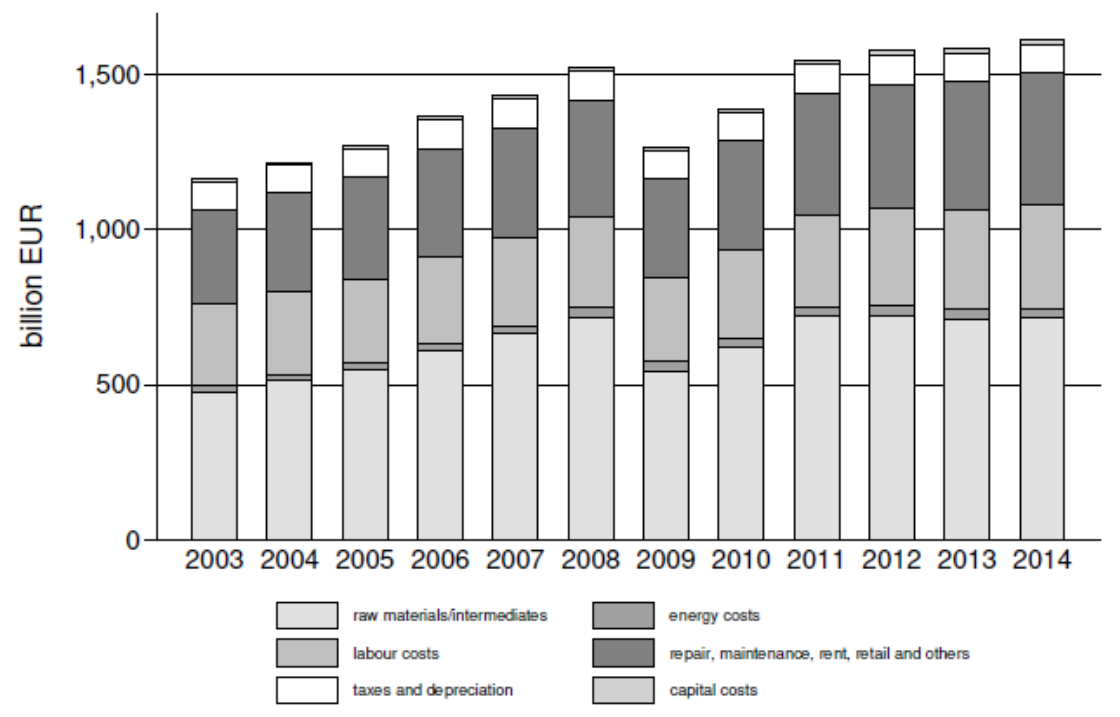

Source: DOI: 10.21242/42251.2003.00.01.1.1.0 to 10.21242/42251.2014.00.01.1.1.0. Own calculations. The sample consists of a subsample of firms in the manufacturing sector.

Figure 13: Development of total costs over time at current prices

between 2003 and 2008 and returned to a high level after the crisis until 2014 when they again started to fall (see Figure 36 in the appendix). According to Eurostat, electricity prices consistently increased between 2007 and 2014 largely due to increases in taxes and levies (see Figure 37 in the appendix). The fact that the cost share increases, but energy intensity does not shift much suggests that energy demand may not be very elastic in manufacturing or that firms expected high energy and electricity prices to be temporary. However, this requires further analysis of the response of individual plants to energy costs.

The energy cost share is not necessarily the best measure of the potential impact of rising energy costs on competitiveness of German plants. The "real unit energy cost" (Energiestückkosten) has been used as an indicator in the monitoring process of the energy transition. This measure relates the energy costs to value added, i.e. the energy requirement in Euros to produce one Euro of value added. While it is more informative than the energy cost share alone, the real unit energy cost underestimates the burden as it does not account for "indirect" energy costs embodied in intermediate inputs. Löschel et al. (2015) estimate that the importance of such indirect energy costs has been increasing sharply over time. Figure 16 shows a kernel density plot of the log-real unit energy cost for the years 2007, 2010 and 2014. There is a clear shift to the right between 2007 and 2010, but very little change between 2010 and 2014, though the distribution seems to be 


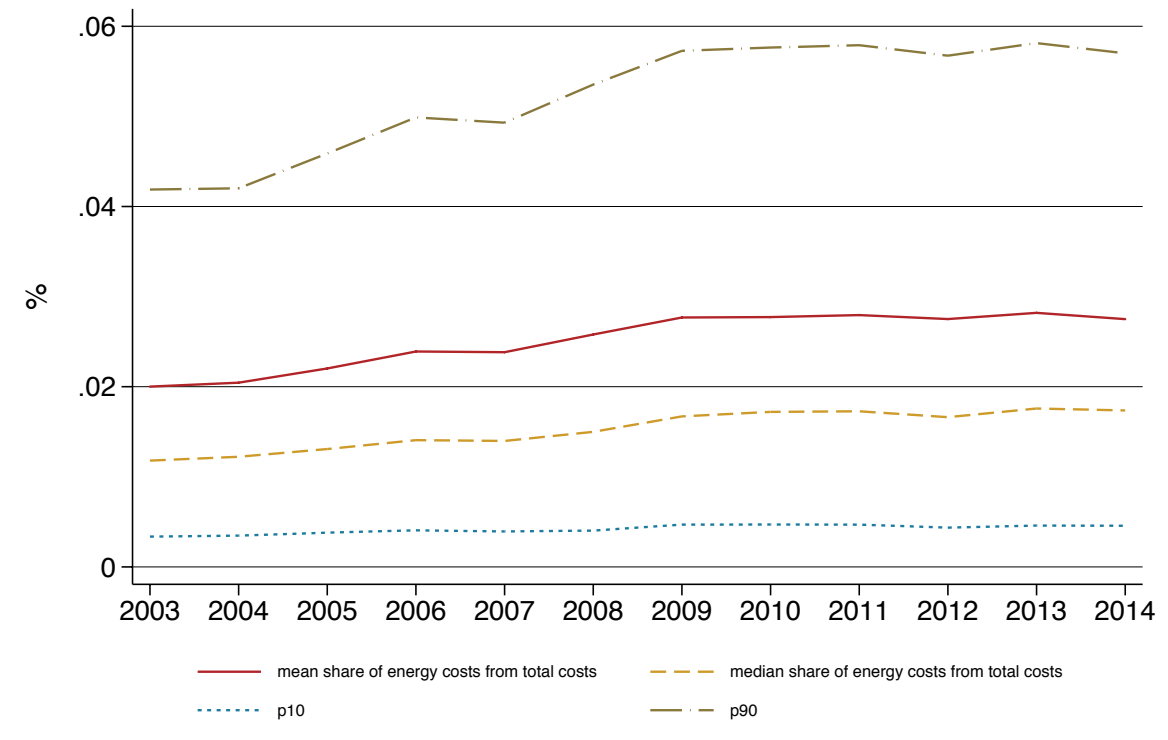

Source: DOI: $10.21242 / 42251.2003 .00 .01 .1 .1 .0$ to $10.21242 / 42251.2014 .00 .01 .1 .1 .0$. Own calculations. The sample consists of a subsample of firms in the manufacturing sector.

Figure 14: Development of mean, median, top and bottom percentiles of energy cost share from total costs over time 


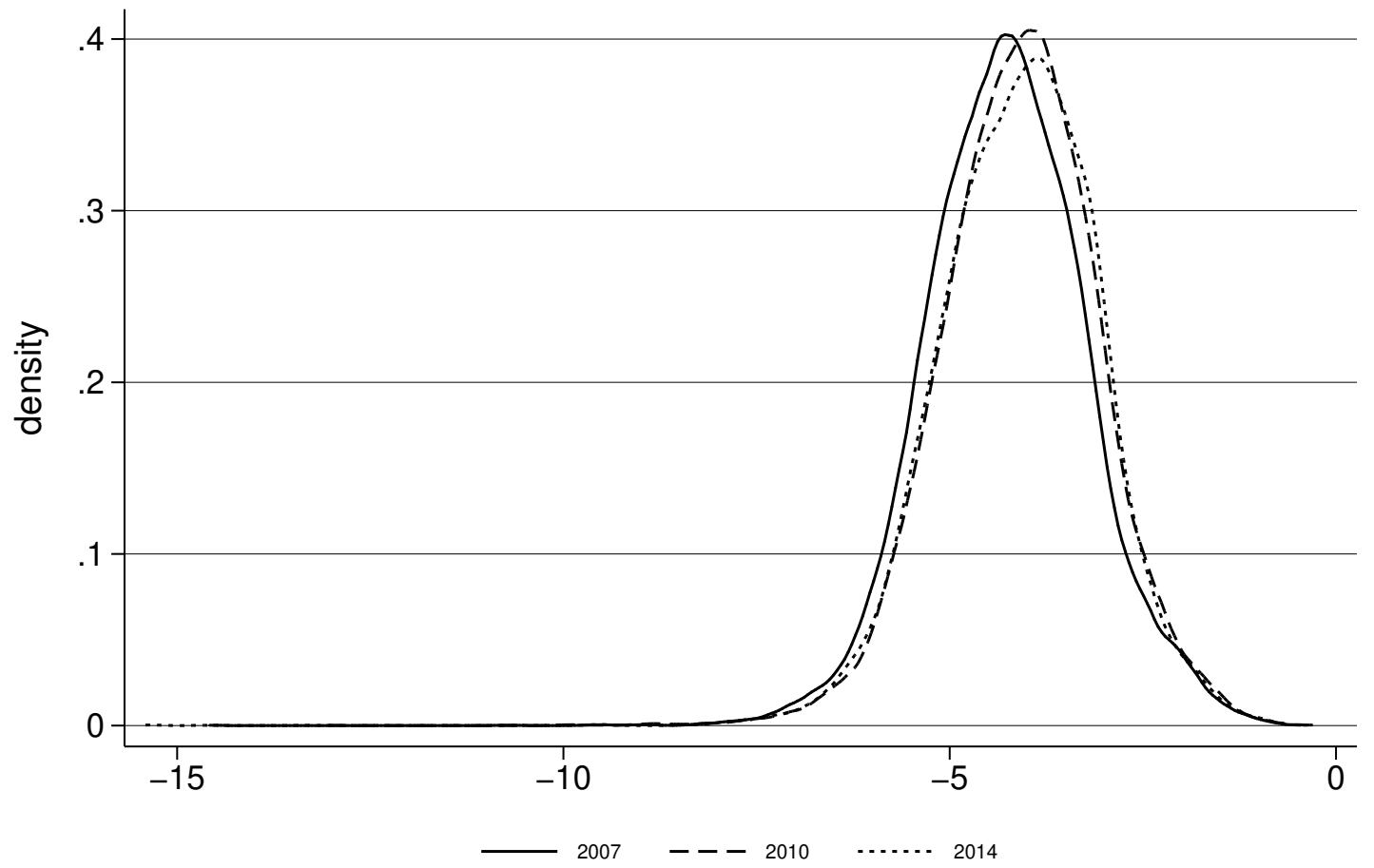

Source: DOI: 10.21242/42251.2003.00.01.1.1.0 to 10.21242/42251.2014.00.01.1.1.0. Own calculations. The graph depicts the Kernel-density of the log-energy share from total costs. The sample consists in a subsample of firms in the German manufacturing sector.

Figure 15: Distribution of log-energy share from total costs for 2007 and 2014 
slightly less concentrated. The median real unit energy cost was around 3 cents per Euro value added in 2003 and increased to 4.7 cents per Euro in 2014. For the 90th percentile, the real unit energy cost increased from 13 cents per Euro value added to 20 cents per Euro, with the strongest increase in the period before the financial crisis in 2009. 


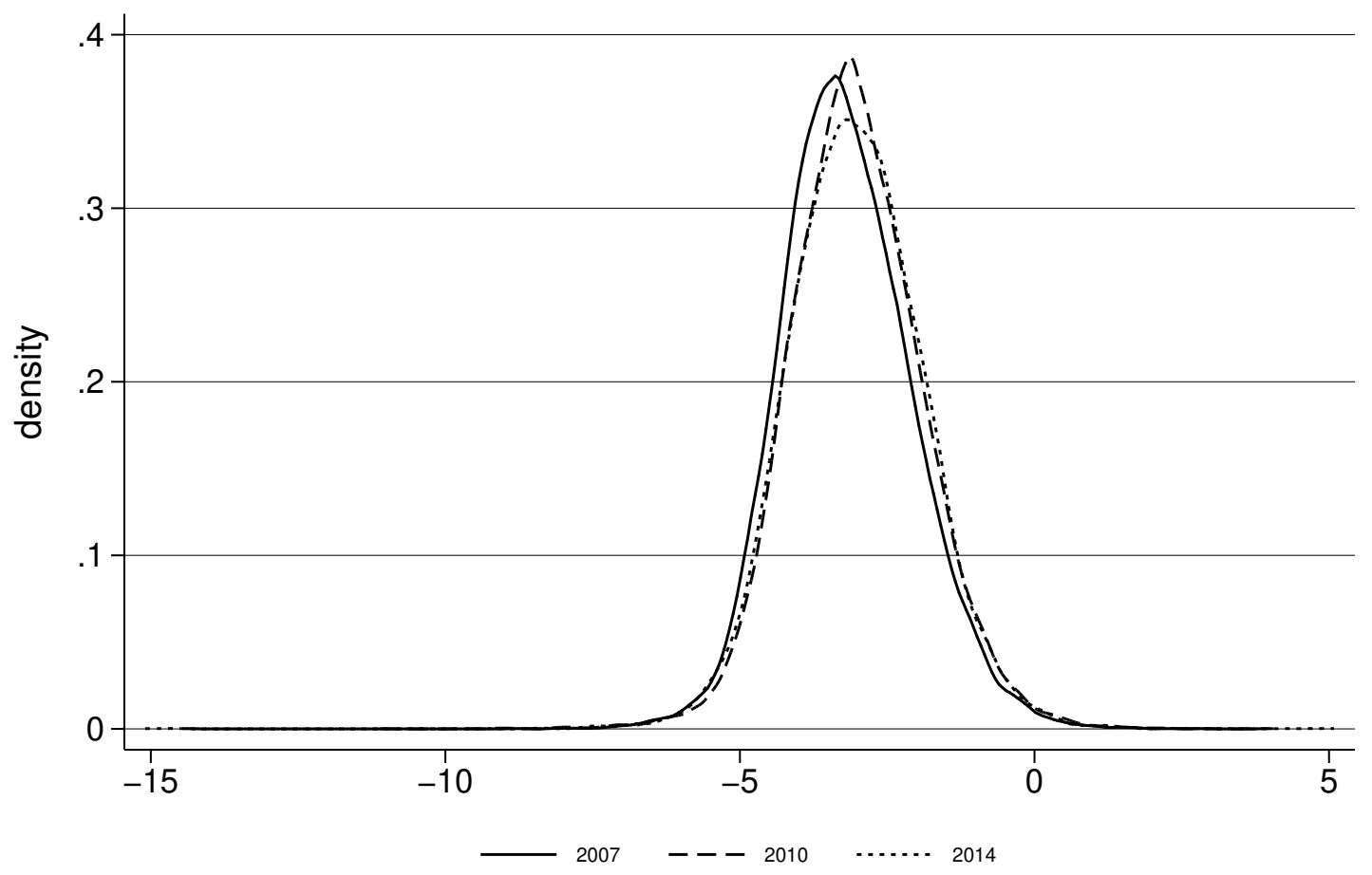

Source: DOI: 10.21242/42251.2003.00.01.1.1.0 to 10.21242/42251.2014.00.01.1.1.0. Own calculations. The graph depicts the Kernel-density of the log of real unit energy cost for the years 2007, 2010 and 2014. The sample consists of the subsample of firms in the German manufacturing sector reporting in the cost structure survey.

Figure 16: Distribution of log-real unit energy costs for 2007, 2010 and 2014 


\section{Sectoral variation in energy use and energy inten- sity}

The difference between average energy use of plants in the German manufacturing sector and the energy use of plants at the 10th percentile of the distribution of energy use depicted in Figure 3 already gave a glimpse of the heterogeneity between manufacturing plants. Petrick et al. (2011) showed that even within more narrowly defined 3-digit sectors, there are large differences between plants. Given this dispersion, this section examines the sectoral variation in energy use and energy intensity in more detail. ${ }^{9}$

Figure 17 shows the ten 3-digit sectors with the highest median energy intensity in 2014 within German manufacturing. Among the top ten sectors with respect to energy intensity are sectors in the ceramics and cement industry (i.e. NACE code 235, 233, 232 and 234). Also the pulp and paper industry (171) and the textiles industry (133) rank among the sectors with the highest median energy intensity. The list closely resembles the one of Petrick et al. (2011) for the year 2006; the sectors that were the most energy intensive ones in 2006 are the same ones that appear in our list for 2014.

The figure also visualizes the within-sector variation in energy intensity: The light bars display the range between top and bottom quartiles, the darker bars show the range between top and bottom deciles of the distribution of energy intensity across plants within a sector. As can be seen, even within quite narrowly defined 3-digit sectors there is substantial variation in the plants' energy intensities that cannot be captured by focusing on the average or median energy-intensity of a sector.

From the bivariate correlations depicted in Figure 18, it can be seen that the sectors with higher median energy intensities tend to also have higher median energy uses, higher median emissions and higher median emission intensities. The correlation between median energy intensity and median electricity share in the energy mix is negative, indicating that the energy-intensive sectors rely more heavily on primary fuels. However, is is notable that as compared to the findings of Petrick et al. (2011), the correlation

\footnotetext{
${ }^{9}$ Some 3-digit sectors in the manufacturing sector are only represented by few plants in the administrative micro-data. Confidentiality however requires a minimal number of observations for each statistic released. In order not to lose those observations and sectors, we merge very small sectors that are not too different with respect to their energy use behaviour together. A list of the merged sectors can be found in the Appendix.
} 


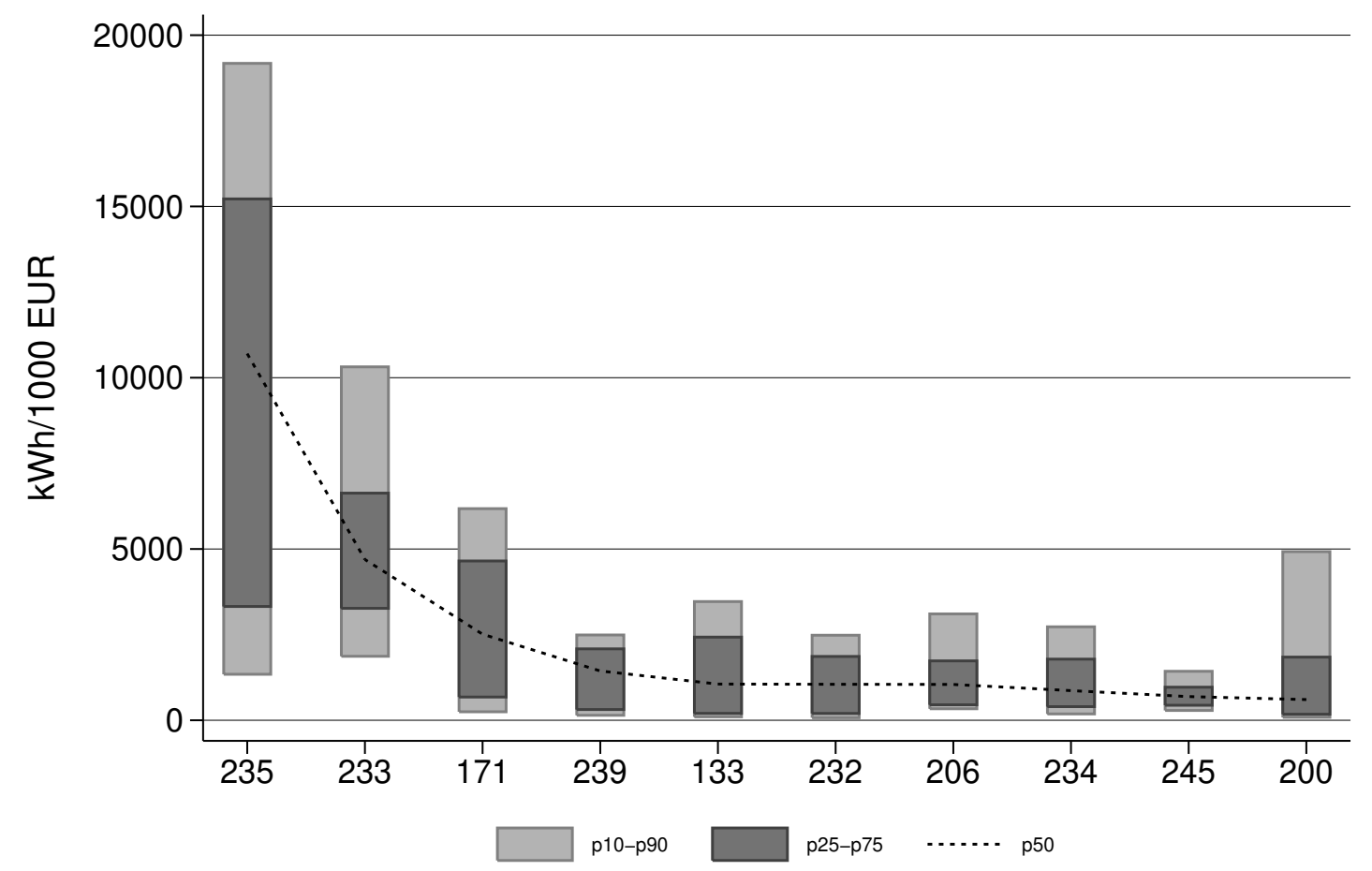

Source: DOI: $10.21242 / 43531.2003 .00 .03 .1 .1 .0$ to $10.21242 / 43531.2014 .00 .03 .1 .1 .0$. and DOI: 10.21242/42111.2003.00.01.1.1.0 to 10.21242/42111.2014.00.01.1.1.0. Own calculations. Note that sector "manufacture of coke" (191) is among the top ten sectors with respect to energy intensity, but cannot be shown for confidentiality reasons.

Figure 17: The ten sectors with the highest median energy intensity in 2014 


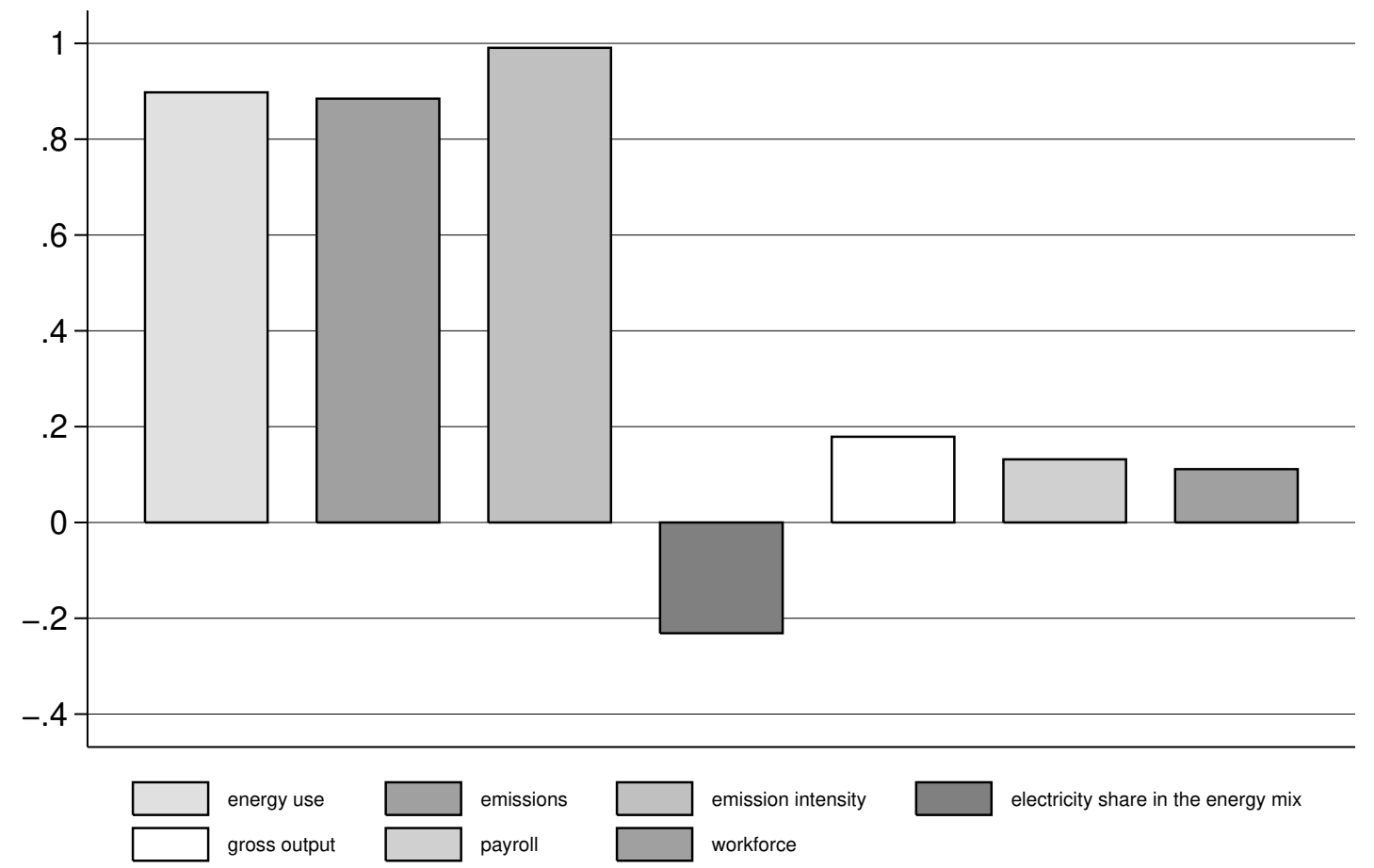

Source: DOI: $10.21242 / 43531.2003 .00 .03 .1 .1 .0$ to $10.21242 / 43531.2014 .00 .03 .1 .1 .0$. and DOI: 10.21242/42111.2003.00.01.1.1.0 to 10.21242/42111.2014.00.01.1.1.0. Own calculations. Correlation coefficients on the dispersion of those variables can be found in Table 6 in the Appendix.

Figure 18: Coefficients of correlation between median energy intensity and different energy and production variables in 2014 (across sectors) 
coefficient has decreased to approximately -0.2 in 2014 as compared to -0.4 in 2006 . It is also notable that there are positive correlations between the median of energy intensity with the median of several production variables (value of output, payroll, workforce), while Petrick et al. (2011) found no correlations.

The sectors that have the highest (lowest) median energy intensity are mostly also among those with the highest (lowest) median energy use and the highest (lowest) median carbon intensity as seen in Figures 28, 29, 30, 31 and 32 in the Appendix. There is no clear pattern between the variation in energy intensity and median energy intensity (as shown in Figure 20), nor between the variation in energy intensity and the variation in energy use or other production variables, as shown in Figure 19. The dispersion of energy intensity and other variables is measured by the interquartile-range-to-median-ratio, i.e. the dispersion of a given variable in a given sector is normalized by the median in order to render the dispersion measure comparable across different distributions with different medians.

Sectors that are very heterogeneous with respect to energy intensity of plants do not necessarily exhibit a large variation with respect to the plants' energy use: Computing a simple bivariate correlation yields a correlation coefficient of only around 0.45 . The same holds for the value of output, payroll and workforce. ${ }^{10}$ The lack of a clear pattern has already been shown by Petrick et al. (2011) for the year 2006 and still holds in 2014. Moreover, sectors with a high median energy-intensity are not necessarily the sectors where there is large variation with respect to energy intensity: The correlation between the sectors' median energy intensities and their interquartile-range-to-medianratio equaled only -0.03 in 2014 . There is substantial variation within sectors, especially with respect to energy use as it was also the case in 2006 according to Petrick et al. (2011).

Sectors within the manufacturing sector are also quite diverse with respect to their fuel mix: Table 2 shows the top ten and bottom five sectors with respect to the fuel share of different fuels in their energy mix. ${ }^{11}$ Overall, the results confirm the earlier intuition: Sectors that are very energy intensive have lower electricity shares in their energy mix.

\footnotetext{
${ }^{10}$ The correlations are reported in Table 6 in the Appendix.

${ }^{11}$ The Table calculates fuel shares in the energy mix on a sector level. This masks the heterogeneity of plants within the sector with respect to their fuel mix. Figures 33, 34 and 35 in the Appendix show the within sector variation in energy and natural gas shares in the energy mix for selected sectors.
} 


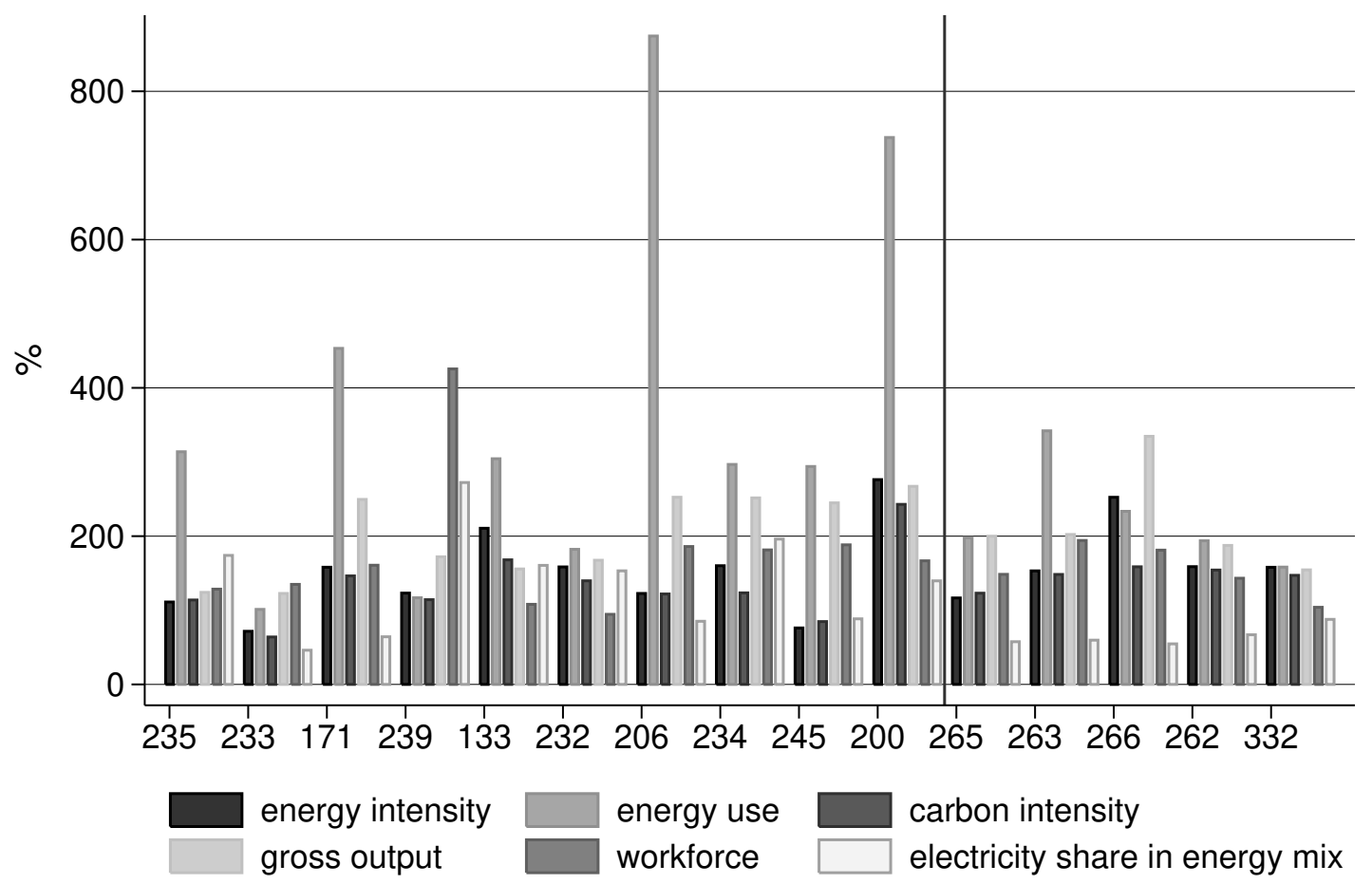

Source: DOI: $10.21242 / 43531.2003 .00 .03 .1 .1 .0$ to $10.21242 / 43531.2014 .00 .03 .1 .1 .0$. and DOI: 10.21242/42111.2003.00.01.1.1.0 to 10.21242/42111.2014.00.01.1.1.0. Own calculations. Note that sector "manufacture of coke" (191) is among the top ten sectors with respect to energy intensity, but cannot be shown for confidentiality reasons.

Figure 19: Variation ((p75-p25)/p50) of several key variables for the ten most and five least energy intensive sectors in 2014 


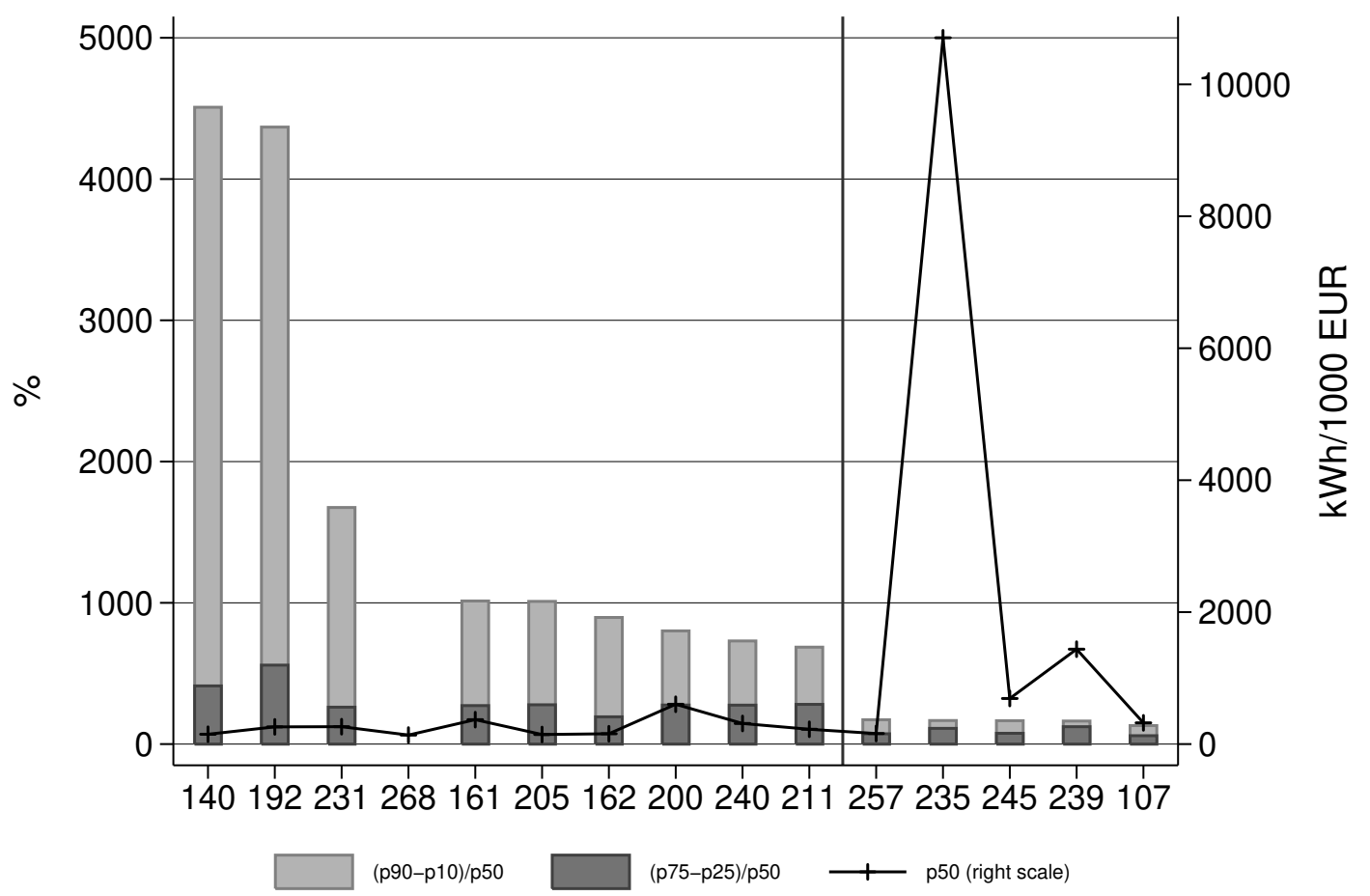

Source: DOI: $10.21242 / 43531.2003 .00 .03 .1 .1 .0$ to $10.21242 / 43531.2014 .00 .03 .1 .1 .0$. and DOI: 10.21242/42111.2003.00.01.1.1.0 to 10.21242/42111.2014.00.01.1.1.0. Own calculations. Sectors are ranked according to ((p90-p10)/p50). Note that sector "manufacture of coke" (191) cannot be shown for confidentiality reasons. For "Manufacture of magnetic and optical media" (268), confidentiality allows only to depict the median.

Figure 20: Variation ((p90-p10)/p50) of energy intensity relative to the median (left) and median of energy intensity (right) for the top ten and bottom five sectors with respect to variation in energy intensity (2014 data) 
Both the Cement industry (235) and the Ceramic industry (233) that are among the top five with respect to their energy intensity in 2014 are among those sectors with the lowest electricity share in 2014. As compared to the results by Petrick et al. (2011), it is notable that, while we find the same sectors to be very coal- and oil-intensive, the shares of those fuels in their energy mix has decreased. This confirms again the occurrence of fuel switching in the German manufacturing sector. 
Table 2: The sectors with the highest and lowest respective fuel share in their 2014 energy mix

Source: DOI: 10.21242/43531.2003.00.03.1.1.0 to 10.21242/43531.2014.00.03.1.1.0. Own calculations. All shares are computed from sector aggregates, including plants with no fuel use. Sectors with the lowest respective fuel share in 2014 (bottom part of the table) are only shown if distinct from zero.

\begin{tabular}{lllllll}
\hline Electricity & Gas & Oil & Heat & Renewables & Coal & Other fuels \\
$72.5 \%: 237$ & $95.5 \%: 191$ & $72.5 \%: 192$ & $53.7 \%: 211$ & $78.2 \%: 161$ & $58.6 \%: 240$ & $34.8 \%: 235$ \\
69.1\%: 268 & $85.6 \%: 233$ & $15.8 \%: 322$ & $31.7 \%: 206$ & $69.8 \%: 162$ & $37.7 \%: 235$ & $4.1 \%: 200$ \\
67.1\%: 257 & $83.2 \%: 232$ & $15.0 \%: 321$ & $23.5 \%: 204$ & $31.7 \%: 310$ & $36.3 \%: 239$ & $3.8 \%: 171$ \\
66.4\%: 273 & $79.1 \%: 234$ & $14.2 \%: 143$ & $22.0 \%: 261$ & $17.4 \%: 171$ & $18.7 \%: 245$ & $1.7 \%: 204$ \\
66.3\%: 261 & $77.3 \%: 231$ & $13.3 \%: 237$ & $21.2 \%: 302$ & $11.9 \%: 322$ & $16.2 \%: 108$ & $1.5 \%: 233$ \\
66.1\%: 272 & $76.3 \%: 133$ & $12.3 \%: 140$ & $19.2 \%: 291$ & $9.7 \%: 172$ & $14.3 \%: 205$ & $1.0 \%: 211$ \\
$65.4 \%: 222$ & $71.4 \%: 105$ & $12.3 \%: 264$ & $17.0 \%: 267$ & $8.5 \%: 323$ & $9.6 \%: 204$ & $0.8 \%: 239$ \\
$64.7 \%: 267$ & $68.9 \%: 109$ & $12.2 \%: 324$ & $15.5 \%: 212$ & $7.2 \%: 107$ & $8.7 \%: 171$ & $0.8 \%: 192$ \\
$64.1 \%: 255$ & $68.4 \%: 100$ & $10.2 \%: 292$ & $14.9 \%: 331$ & $6.9 \%: 252$ & $5.8 \%: 252$ & $0.4 \%: 244$ \\
$63.0 \%: 279$ & $63.3 \%: 236$ & $9.0 \%: 331$ & $13.3 \%: 100$ & $6.9 \%: 273$ & $5.6 \%: 133$ & $0.4 \%: 221$ \\
\hline $11.8 \%: 235$ & $11.7 \%: 261$ & $0.3 \%: 171$ & & & & \\
$10.8 \%: 240$ & $9.8 \%: 162$ & $0.3 \%: 272$ & & & & \\
$10.2 \%: 233$ & $8.8 \%: 237$ & $0.1 \%: 206$ & & & & \\
$7.2 \%: 192$ & $5.1 \%: 235$ & $0.1 \%: 268$ & & & & \\
$4.5 \%: 191$ & $0.2 \%: 161$ & $0 \%: 191$ & & & & \\
\hline
\end{tabular}




\section{Conclusion}

The manufacturing sector accounts for a substantial share of German GDP, employment and carbon emissions. Therefore, the manufacturing sector's energy use and carbon emissions are of crucial importance for reaching Germany's climate goals. In this paper, we analyse energy use patterns in the German manufacturing sector between 2003 and 2014, using a rich data set of administrative micro-data. We show that although the manufacturing sector has been faced with rising energy costs as a share of total costs, energy use has not declined (except briefly during the economic crisis). We also find that energy intensity in the manufacturing sector has not decreased substantially. In contrast, carbon intensity has been reduced slightly between 2003 and 2014. This can be attributed to changes in the fuel mix in the manufacturing sector: In particular, we show that oil is declining in terms of aggregate use over the years, while gas is becoming more important. In the period we also observe a substantial increase in electricity selfgeneration in the manufacturing sector. Whether this shift is due to regulation, e.g. rising electricity charges and exemptions for self-generated electricity is an important question for future research. The manufacturing sector remains very heterogeneous in terms of energy use: In our paper, we confirm the findings by Petrick et al. (2011) and show that also in 2014, sectors within German manufacturing are very different in terms of their energy use, energy intensity and emissions intensity. We find that even within 3-digit sectors, plants vary substantially with regards to their energy use behaviour. Our paper sheds light on how energy use patterns in the manufacturing sector have evolved over time. The extent to which these developments have been driven by policy or fuel prices is unclear. Further research should address the causal impact of individual policy measures and their interaction effects to identify potential for improving policy design and achieving further necessary reductions in carbon emissions.

\section{Acknowledgements}

We thank Robert Germeshausen, Andreas Gerster, and Ulrich Wagner for suggestions and insightful comments. We also thank participants of the seminars at the ZEW-LeibnizCentre for European Economic Research. We gratefully acknowledge the Research Data Centre (FDZ) of the Federal Statistical Office and the Statistical Offices of the German 
Länder for granting us access to the AFiD data and for the use of their research facilities, in particular Michael Rößner, Stefan Seitz and Diane Zabel for their advice and technical support. We thank the Federal Ministry of Education and Research (BMBF) for the financial support through the Kopernikus-Project ENavi (Grant number 03SFK4Z0) and TRACE (Grant number 01LA1815A). The views expressed in this paper are those of the authors and do not necessarily represent those of the institutions mentioned above. 


\section{References}

DeStatis (2018). Erzeugerpreisindex gewerblicher Produkte. Available under: https://www.destatis.de/DE/Themen/Wirtschaft/Preise/Erzeugerpreisindexgewerbliche-Produkte/_inhalt.html.

— (2019). Bruttoinlandsprodukt 2018 für Deutschland.

Löschel, A., Kaltenegger, O. and Baikowski, M. (2015). Die Rolle der indirekten Energiekosten im deutschen Produzierenden Gewerbe. Wirtschaftsdienst, (12), 837844 .

Petrick, S., Rehdanz, K. and Wagner, U. J. (2011). Energy Use Patterns in German Industry: Evidence from Plant-level Data. Jahrbücher für Nationalökonomie und Statistik, 231 (3), 379-414.

Umweltbundesamt (2016). Carbon Dioxide Emissions for the German Atmospheric Emission Reporting 1990-2014.

— (2018a). Bestimmung spezifischer Treibhausgas-Emissionsfaktoren für Fernwärme. Climate Change, $\mathbf{0 8 / 0 8 .}$

- (2018b). Entwicklung der spezifischen Kohlendioxid-Emissionen des deutschen Strommix in den Jahren 1990-2017. Climate Change, 11/2018. 
7 Appendix 
Table 3: Emission factors for different fuels and electricity procured

\begin{tabular}{|c|c|c|c|c|c|c|c|c|c|c|c|c|c|}
\hline & All years & 2003 & 2004 & 2005 & 2006 & 2007 & 2008 & 2009 & 2010 & 2011 & 2012 & 2013 & 2014 \\
\hline Electricity & & 639 & 618 & 616 & 623 & 642 & 605 & 582 & 574 & 573 & 596 & 607 & 595 \\
\hline District heat ${ }^{12}$ & 332.4 & & & & & & & & & & & & \\
\hline Natural gas/associated gas & 201.6 & & & & & & & & & & & & \\
\hline Liquified gas & & 233.8 & 234.9 & 235.1 & 235.3 & 239.8 & 234.8 & 234.9 & 235.2 & 235.4 & 235.4 & 235.5 & 235.9 \\
\hline Light fuel oil & 266.5 & & & & & & & & & & & & \\
\hline Hard coal & & 337.9 & 338 & 337.9 & 338.2 & 337.7 & 339.5 & 338.8 & 338.5 & 339.2 & 337.2 & 336.1 & 336.8 \\
\hline Coke & 389.3 & & & & & & & & & & & & \\
\hline Raw lignite & & 392.8 & 393.2 & 389.6 & 386.3 & 386.5 & 383.3 & 381.8 & 382.8 & 381.7 & 377.9 & 378.5 & 373.6 \\
\hline Brown coal briquettes & & 356.4 & 357.4 & 357.4 & 356.4 & 358.7 & 359.4 & 357.7 & 356.4 & 357.4 & 357.4 & 356.7 & 358.4 \\
\hline Heavy fuel & & 287.1 & 287.1 & 286.4 & 286.9 & 287.2 & 288.3 & 284.2 & 286.9 & 287.5 & 288.2 & 288 & 292.8 \\
\hline Other coal products ${ }^{13}$ & 276.1 & & & & & & & & & & & & \\
\hline Other petroleum products ${ }^{14}$ & & 277.2 & 277.7 & 277.1 & 277.2 & 277.7 & 278.2 & 281.6 & 284.9 & 282.2 & 282.5 & 282.6 & 282.2 \\
\hline Renewables & $0^{15}$ & & & & & & & & & & & & \\
\hline Other gas products ${ }^{16}$ & & 332.7 & 332.6 & 327.2 & 330.8 & 323.9 & 331.4 & 339.3 & 333 & 338.5 & 337.2 & 334.1 & 331.1 \\
\hline Industrial waste and other fuels & & 256 & 256 & 256.1 & 256.1 & 256.1 & 256.1 & 256 & 256 & 256 & 256 & 256 & 256 \\
\hline
\end{tabular}


${ }^{12}$ Emission factors for heat are taken from Umweltbundesamt (2018a). This publication contains emission factors for the years 2000 and 2005 ; since it is not clear whether this yields more reliable emission factors, we abstain from extrapolating the emission factors between 2000 and 2005 and just use the 2005 emission factor. Measurement error with respect to the emission factor for district heat should not have large consequences, since per year less than 3.500 plants use heat (before data cleansing)

${ }^{13}$ The emission factor is calculated by taking the average of the emission factors from hard coal briquettes, other coal products, brown coal coke, fluidized bed coal and pulverized coal. Since it is not clear to which weights those coal products are contained in the variable "other coal products", we use a simple unweighted average here. Less than 250 plants per year consume other coal products.

${ }^{14}$ The emission factor is obtained by taking the unweighted average of the emission factors of other petroleum products, diesel oil, refinery gas and petroleum coke. Users of other petroleum products amount to less than 210 per year

${ }^{15}$ For renewable energy sources, we use an emission factor of 0 . While in principle, also burning biomass or landfill gas is associated with emissions, hydropower or solar power do not cause emissions. From our data, it is hard to distinguish those cases and to assign an appropriate emission factor. Therefore we use an emission factor of 0 as has also been done in previous studies (e.g. Petrick et al. 2011)

${ }^{16}$ The emission factors consist of unweighted averages of the emission factors of coke oven gas, blast furnace and converter gas, other gases and mine gas. Weights on the different components of "other gas products" are unavailable. However, other gas products are used by few plants in any case (maximally 50 plants per year) 
Table 4: Users and aggregate use of different fuels in 2014

Source: DOI: 10.21242/43531.2003.00.03.1.1.0 to 10.21242/43531.2014.00.03.1.1.0. Own calculations.

\begin{tabular}{lll}
\hline & number of users & aggregate use (TWh) \\
Electricity & 41.459 & 217 \\
Gas & 28.747 & 344 \\
Oil & 14.967 & 84 \\
Coal & 389 & 148 \\
Heat & 3.180 & 47 \\
Renewables & 1.835 & 36 \\
Others & 116 & 22 \\
\hline
\end{tabular}

Table 5: List of merged sectors:

\begin{tabular}{ll}
\hline Merged sector code & Original sector code \\
100 & The fruit and vegetable processing industry (103) \\
& Manufacture of vegetable and animal oils and fats (104) \\
& Beverage production (110) \\
& Tobacco processing (120) \\
& Manufacture of wearing apparel, except fur apparel (141) \\
& Manufacture of articles of fur (142) \\
& The production of printing products (181) \\
& The reproduction services of recorded media (182) \\
& Manufacture of basic chemicals, fertilisers and nitrogen compounds, plastics and synthetic rubber in \\
& primary forms (201) \\
& Manufacture of pesticides and other agro-chemical products (202 \\
& Manufacture of basic iron and steel and of ferro-alloys (241) \\
& Manufacture of tubes, pipes, hollow profiles and related fittings of steel (242) \\
& Manufacture of air and spacecraft and related machinery (303) \\
& Manufacture of military fighting vehicles (304) \\
\hline
\end{tabular}




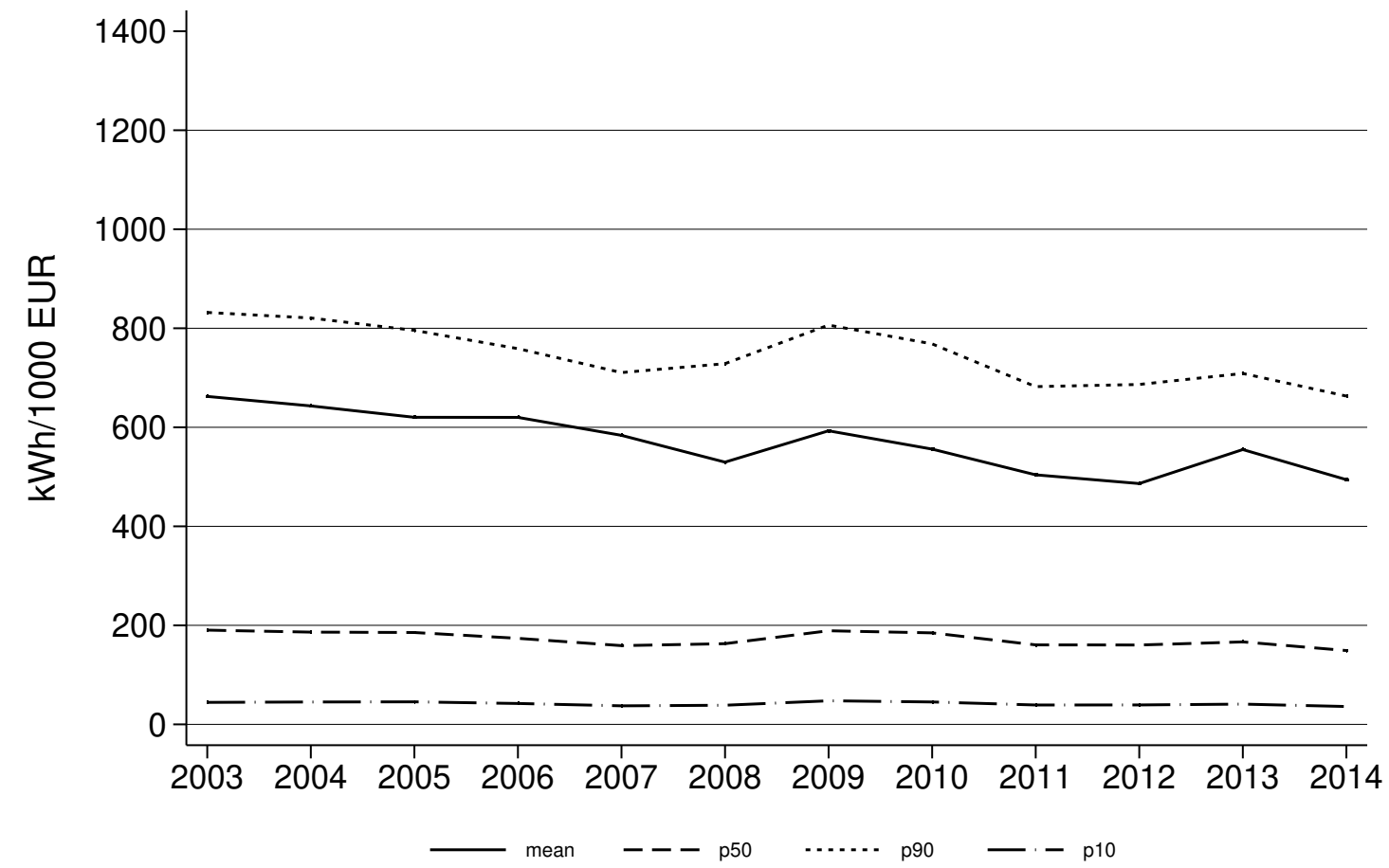

Source: DOI: $10.21242 / 43531.2003 .00 .03 .1 .1 .0$ to $10.21242 / 43531.2014 .00 .03 .1 .1 .0$. and DOI: 10.21242/42111.2003.00.01.1.1.0 to 10.21242/42111.2014.00.01.1.1.0. Own calculations. The sectors 131, 133, 254, 256, 268, 301, 303, 304, 329, 331 and 332 are not included/not included for the whole time period in this graph.

Figure 21: Aggregate energy intensity in current prices for the sample for which price deflators are available 


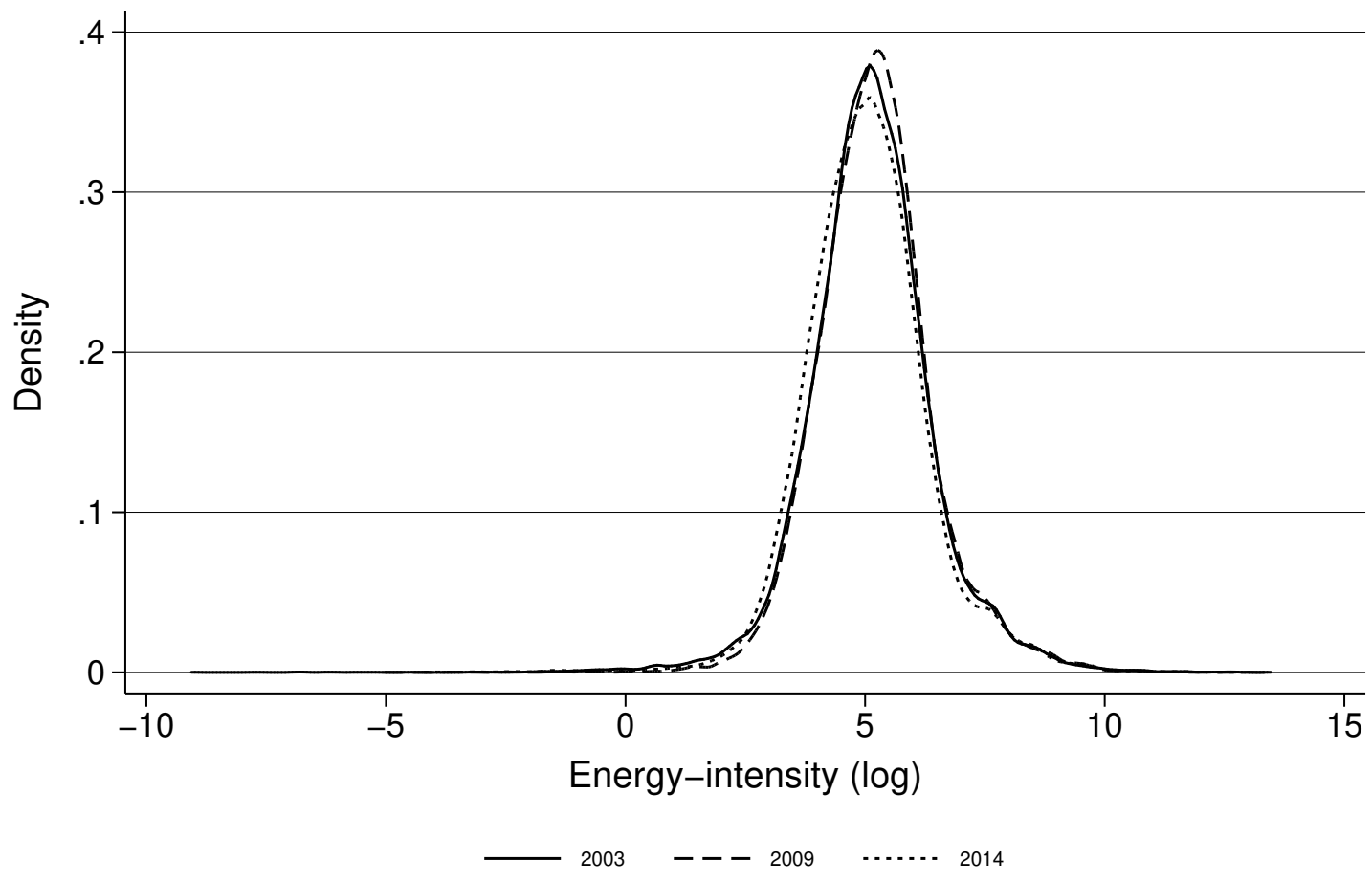

Source: DOI: $10.21242 / 43531.2003 .00 .03 .1 .1 .0$ to $10.21242 / 43531.2014 .00 .03 .1 .1 .0$. and DOI: 10.21242/42111.2003.00.01.1.1.0 to 10.21242/42111.2014.00.01.1.1.0. Own calculations. The graph depicts the Kernel-density of the logartihm of deflated energy intensity. Information on price deflators are taken from DeStatis (2018).

Figure 22: Distribution of log-energy intensity at 2015 prices in 2003, 2009 and 2014 


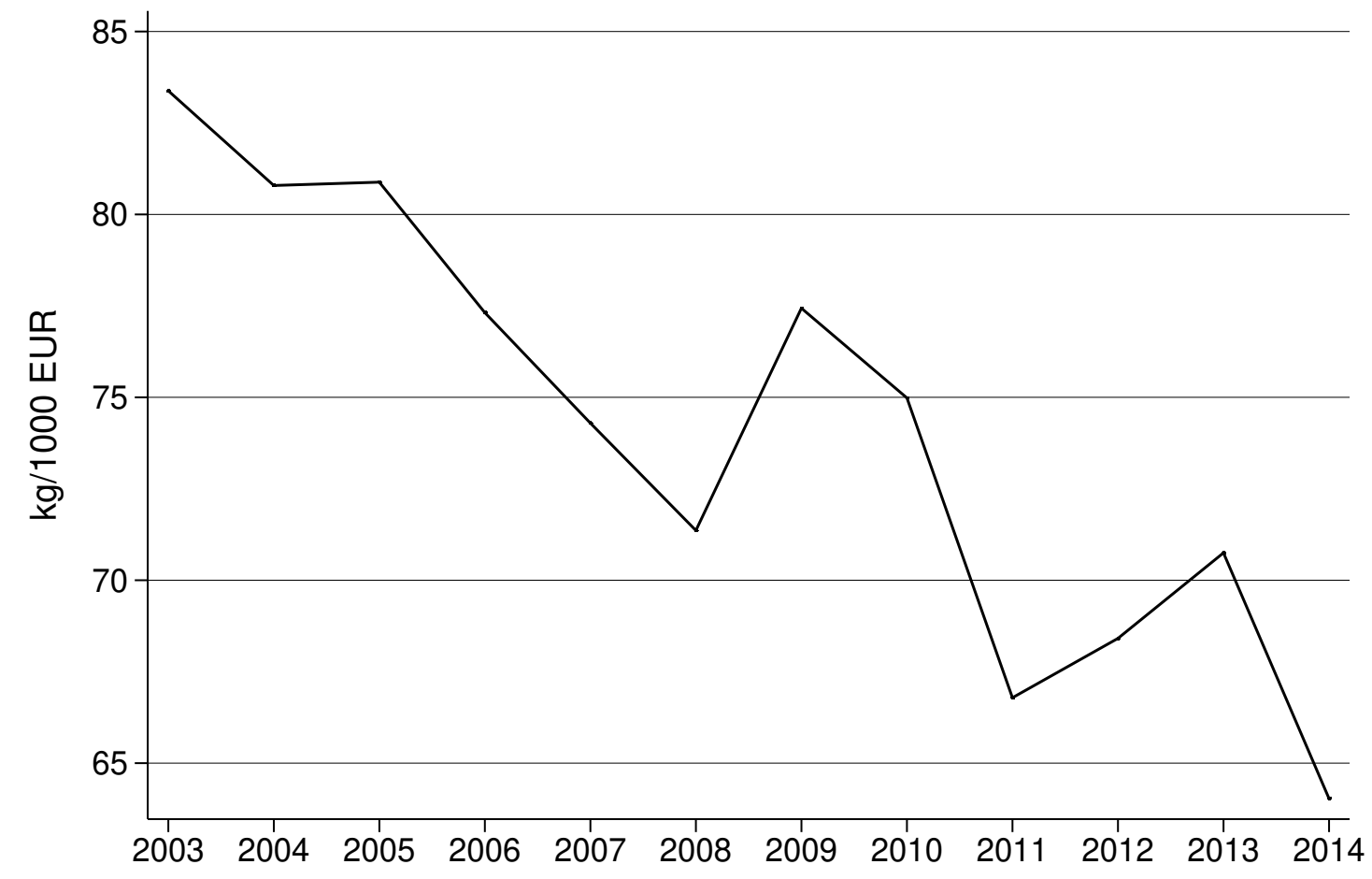

Source: DOI: $10.21242 / 43531.2003 .00 .03 .1 .1 .0$ to $10.21242 / 43531.2014 .00 .03 .1 .1 .0$. and DOI: 10.21242/42111.2003.00.01.1.1.0 to 10.21242/42111.2014.00.01.1.1.0. Own calculations. Information on price deflators are taken from DeStatis (2018).

Figure 23: Development of median carbon intensity over time at 2015 prices 


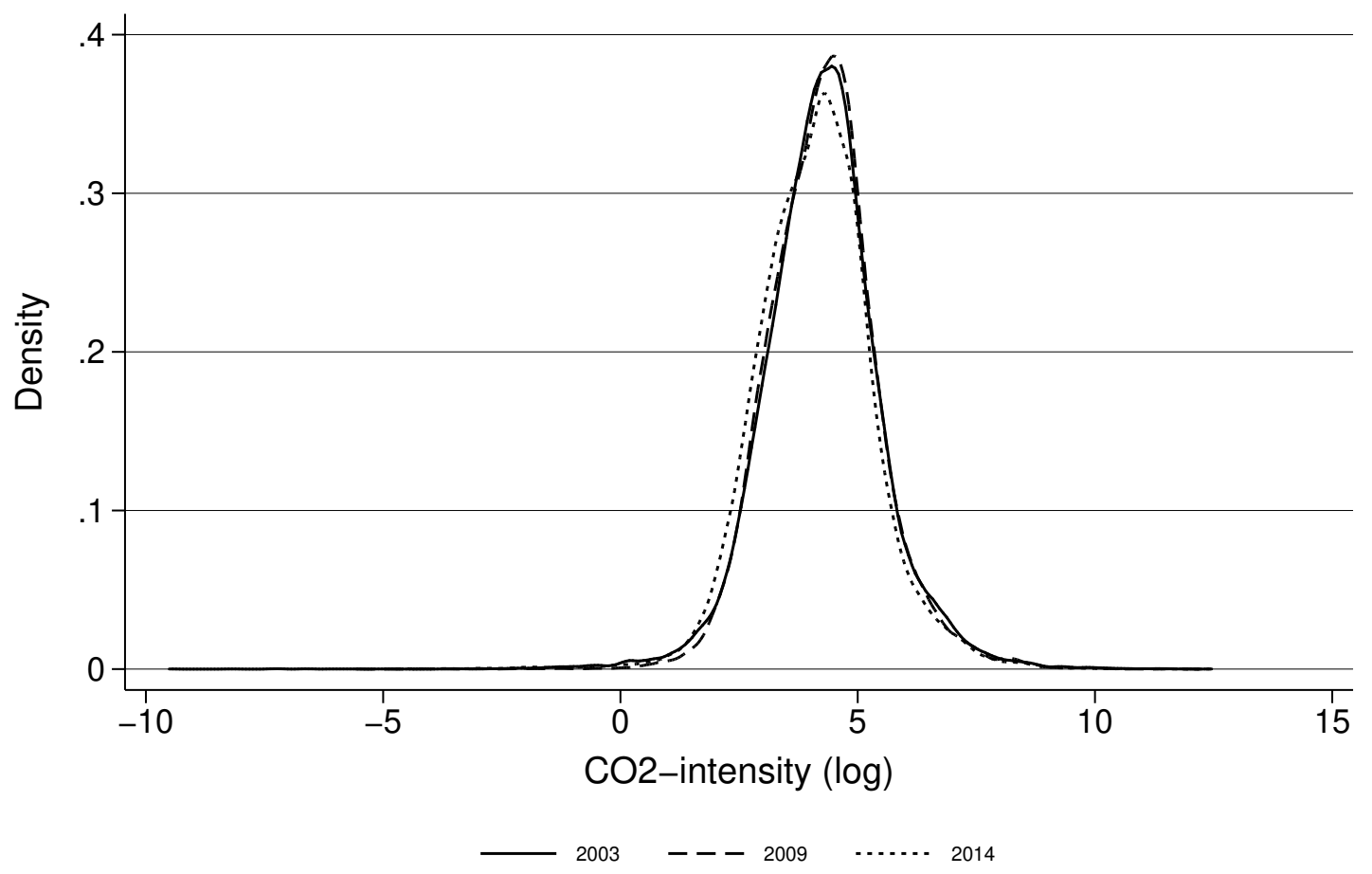

Source: DOI: $10.21242 / 43531.2003 .00 .03 .1 .1 .0$ to $10.21242 / 43531.2014 .00 .03 .1 .1 .0$. and DOI: 10.21242/42111.2003.00.01.1.1.0 to 10.21242/42111.2014.00.01.1.1.0. Own calculations. The graph depicts the Kernel-density of the logartihm of deflated carbon intensity. Information on price deflators are taken from DeStatis (2018).

Figure 24: Distribution of log-carbon intensity at 2015 prices in 2003, 2009 and 2014 


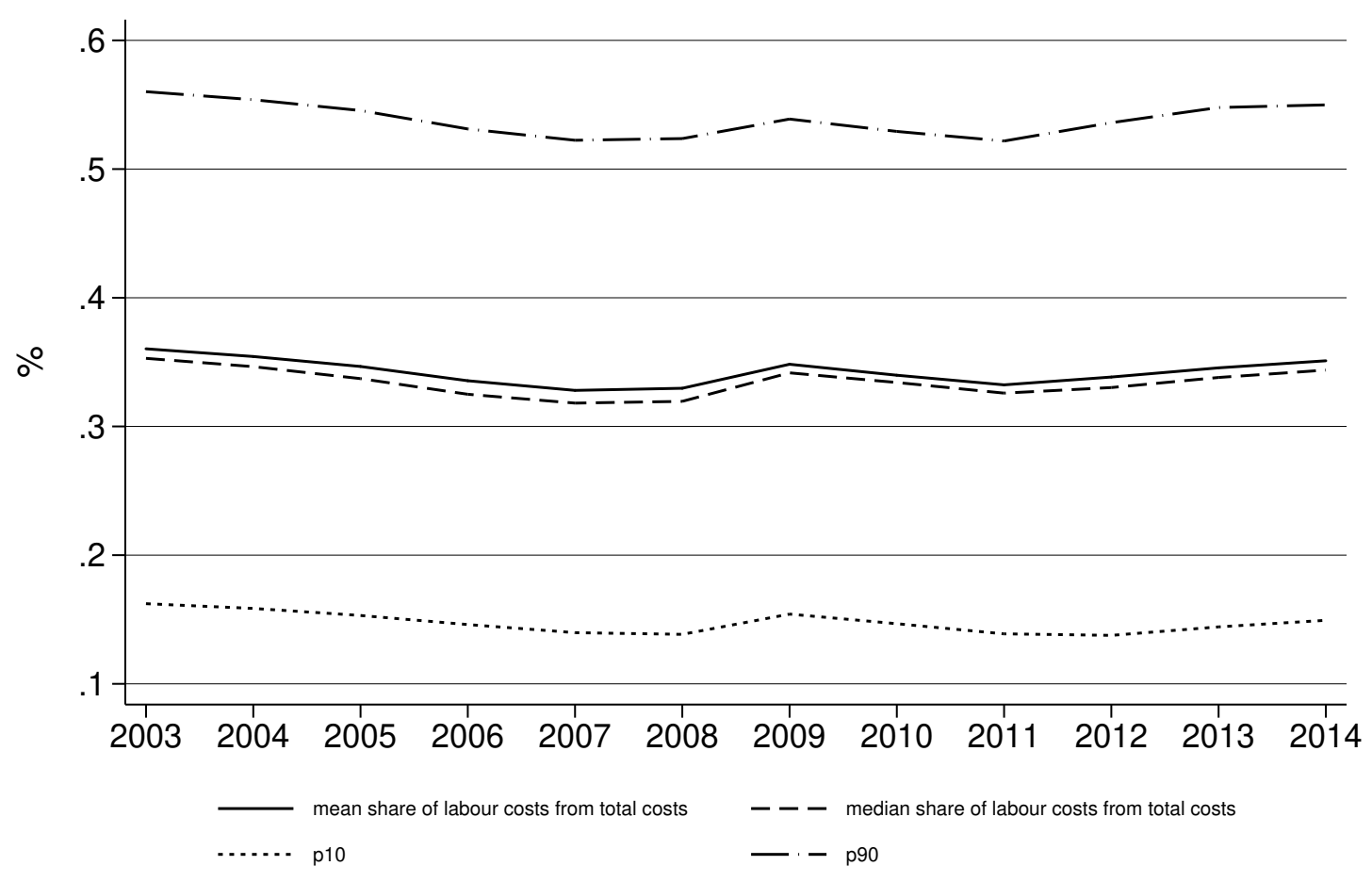

Source: DOI: $10.21242 / 42251.2003 .00 .01 .1 .1 .0$ to $10.21242 / 42251.2014 .00 .01 .1 .1 .0$. Own calculations. The sample consists of a subsample of firms in the manufacturing sector.

Figure 25: Development of labour cost share from total costs over time 


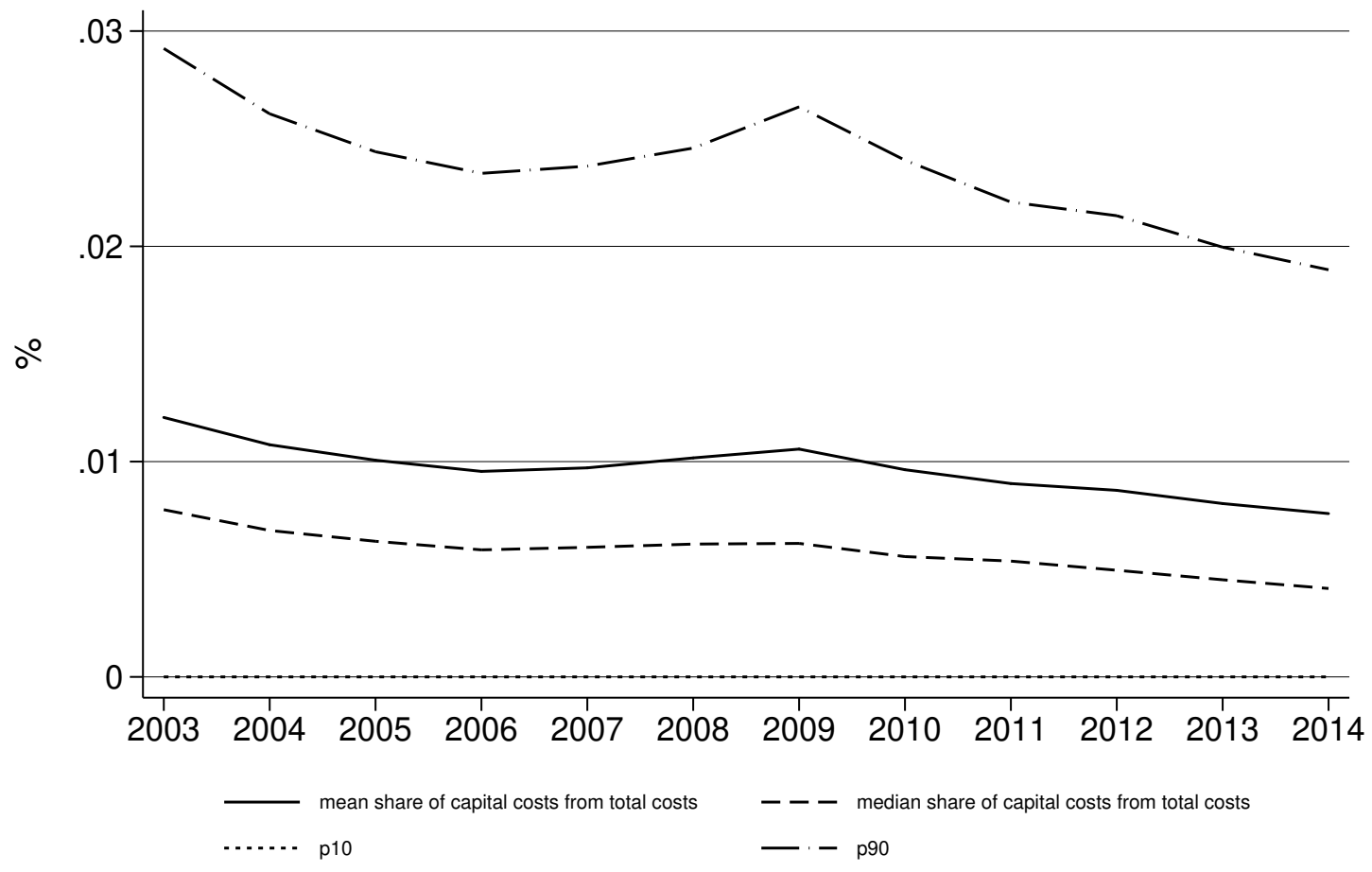

Source: DOI: $10.21242 / 42251.2003 .00 .01 .1 .1 .0$ to $10.21242 / 42251.2014 .00 .01 .1 .1 .0$. Own calculations. The sample consists of a subsample of firms in the manufacturing sector.

Figure 26: Development of capital cost share from total costs over time 


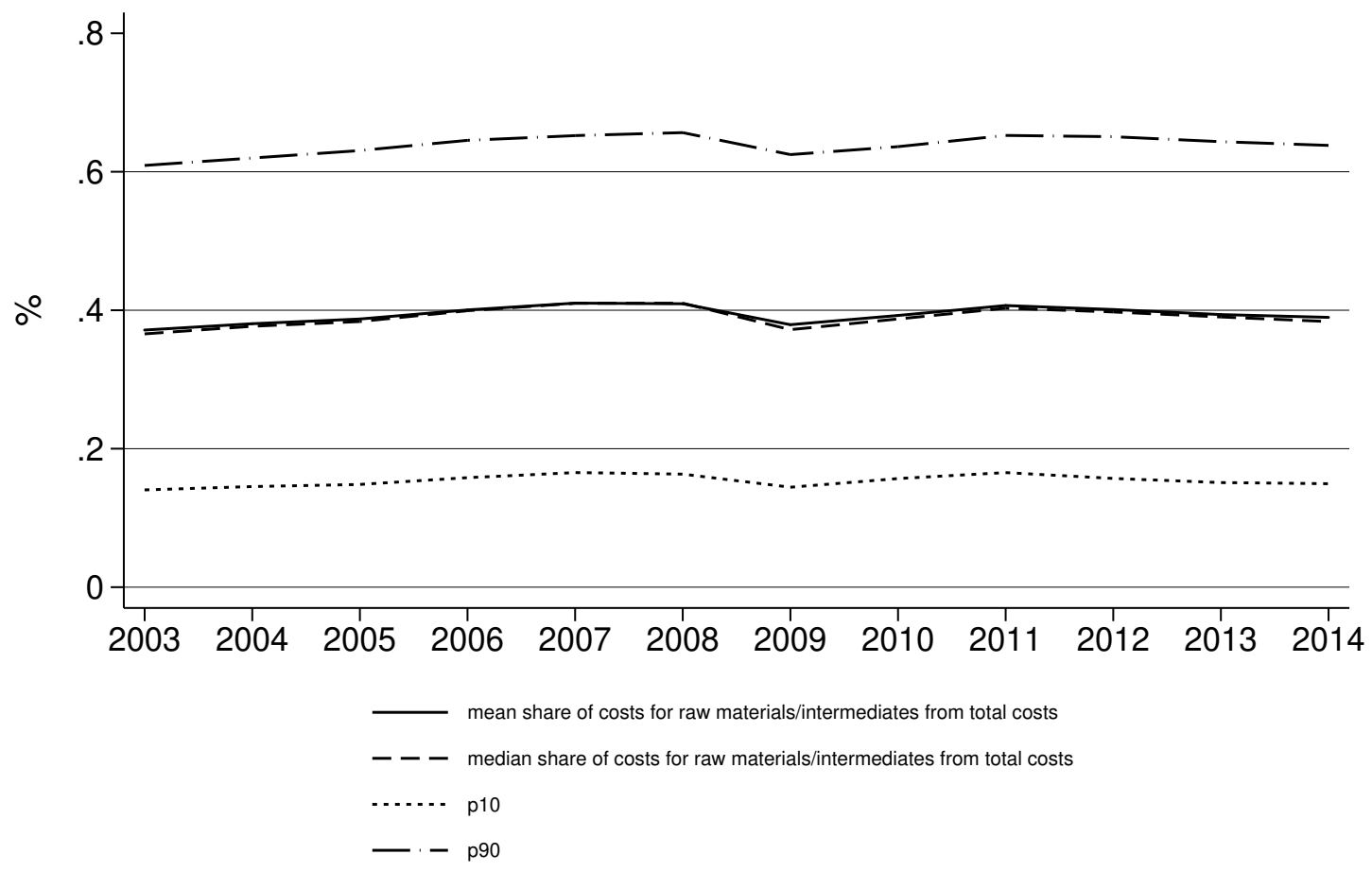

Source: DOI: $10.21242 / 42251.2003 .00 .01 .1 .1 .0$ to $10.21242 / 42251.2014 .00 .01 .1 .1 .0$. Own calculations. The sample consists of a subsample of firms in the manufacturing sector.

Figure 27: Development of resource/intermediate inputs cost share from total costs over time 


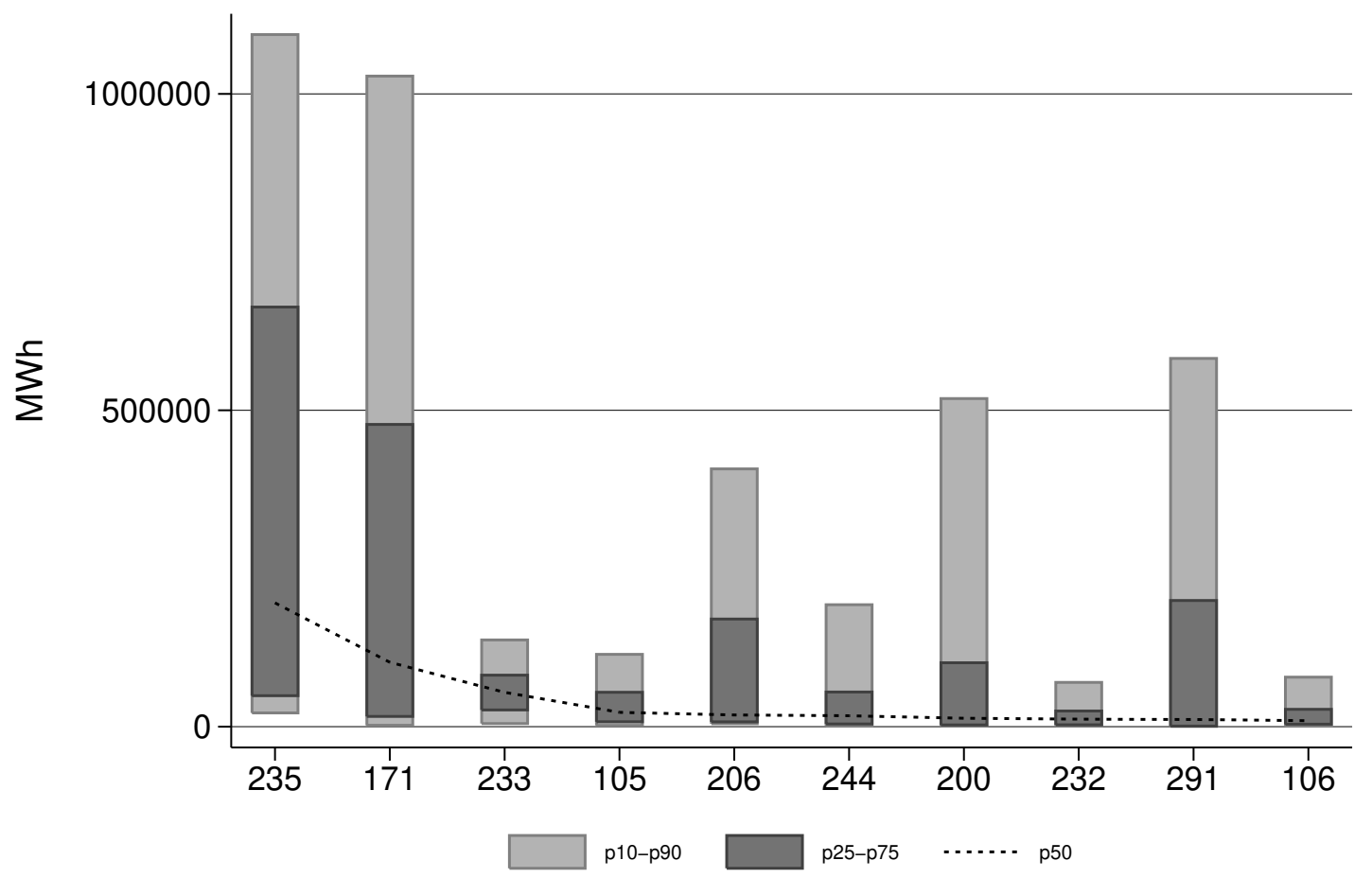

Source: DOI: $10.21242 / 43531.2003 .00 .03 .1 .1 .0$ to $10.21242 / 43531.2014 .00 .03 .1 .1 .0$. and DOI: 10.21242/42111.2003.00.01.1.1.0 to 10.21242/42111.2014.00.01.1.1.0. Own calculations. Note that sector "manufacture of coke" (191) is among the top ten sectors with respect to energy use, but cannot be shown for confidentiality reasons.

Figure 28: The ten sectors with the highest median energy use in 2014 


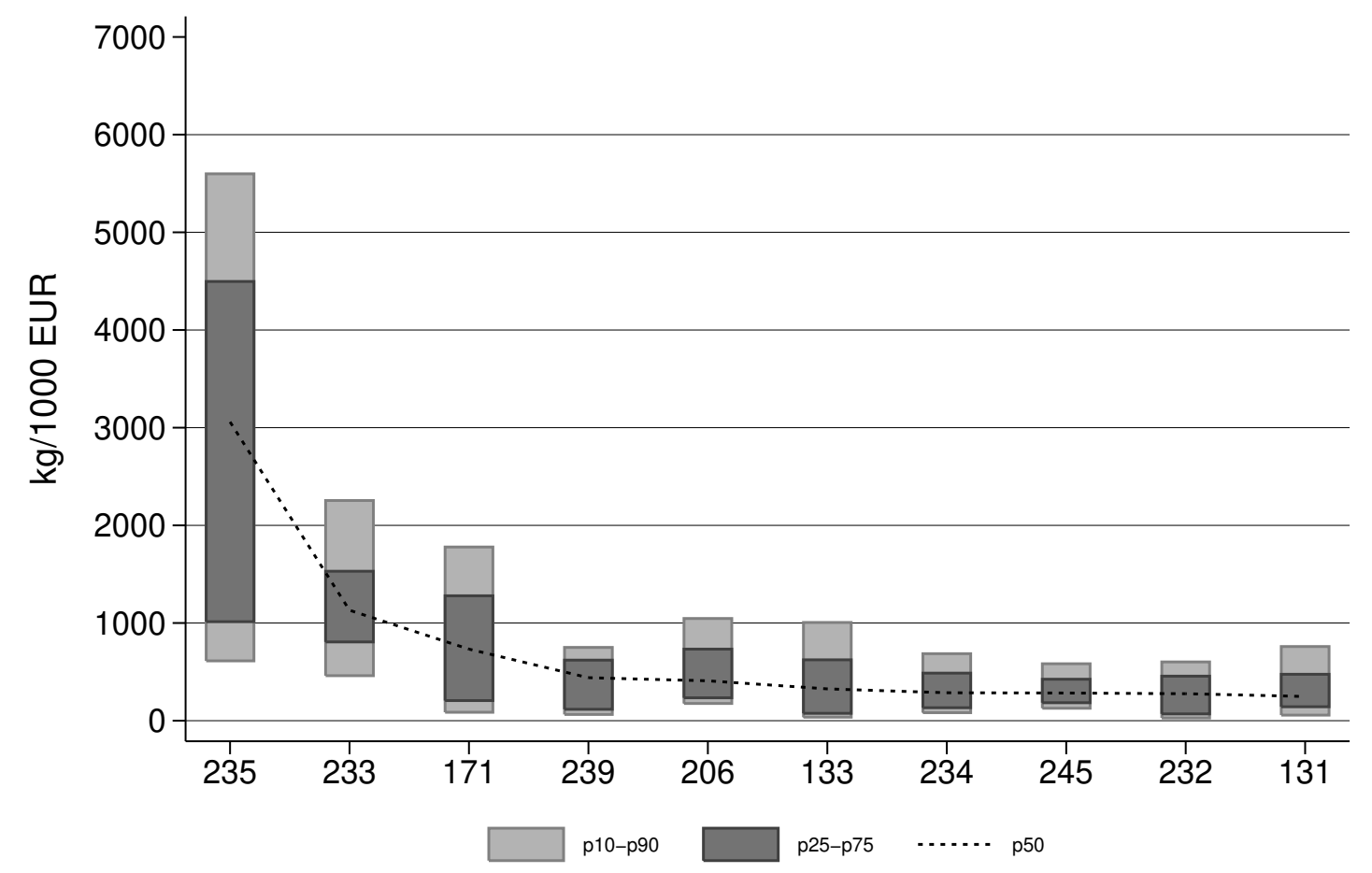

Source: DOI: $10.21242 / 43531.2003 .00 .03 .1 .1 .0$ to $10.21242 / 43531.2014 .00 .03 .1 .1 .0$. and DOI: 10.21242/42111.2003.00.01.1.1.0 to 10.21242/42111.2014.00.01.1.1.0. Own calculations. Note that sector "manufacture of coke" (191) is among the top ten sectors with respect to carbon intensity, but cannot be shown for confidentiality reasons.

Figure 29: The ten sectors with the highest median carbon intensity in 2014 


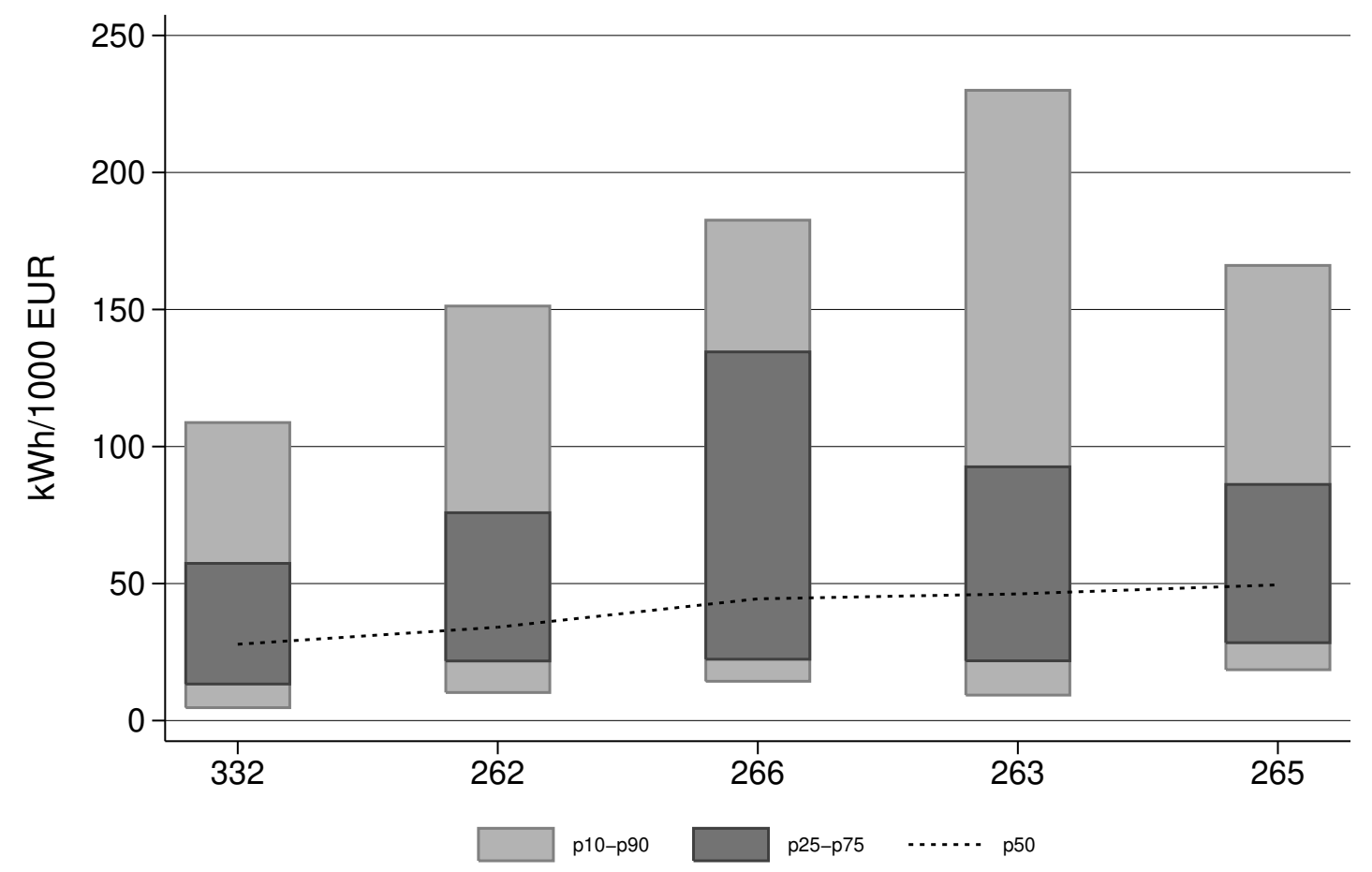

Source: DOI: $10.21242 / 43531.2003 .00 .03 .1 .1 .0$ to $10.21242 / 43531.2014 .00 .03 .1 .1 .0$. and DOI: 10.21242/42111.2003.00.01.1.1.0 to 10.21242/42111.2014.00.01.1.1.0. Own calculations.

Figure 30: The five sectors with the lowest median energy intensity in 2014 


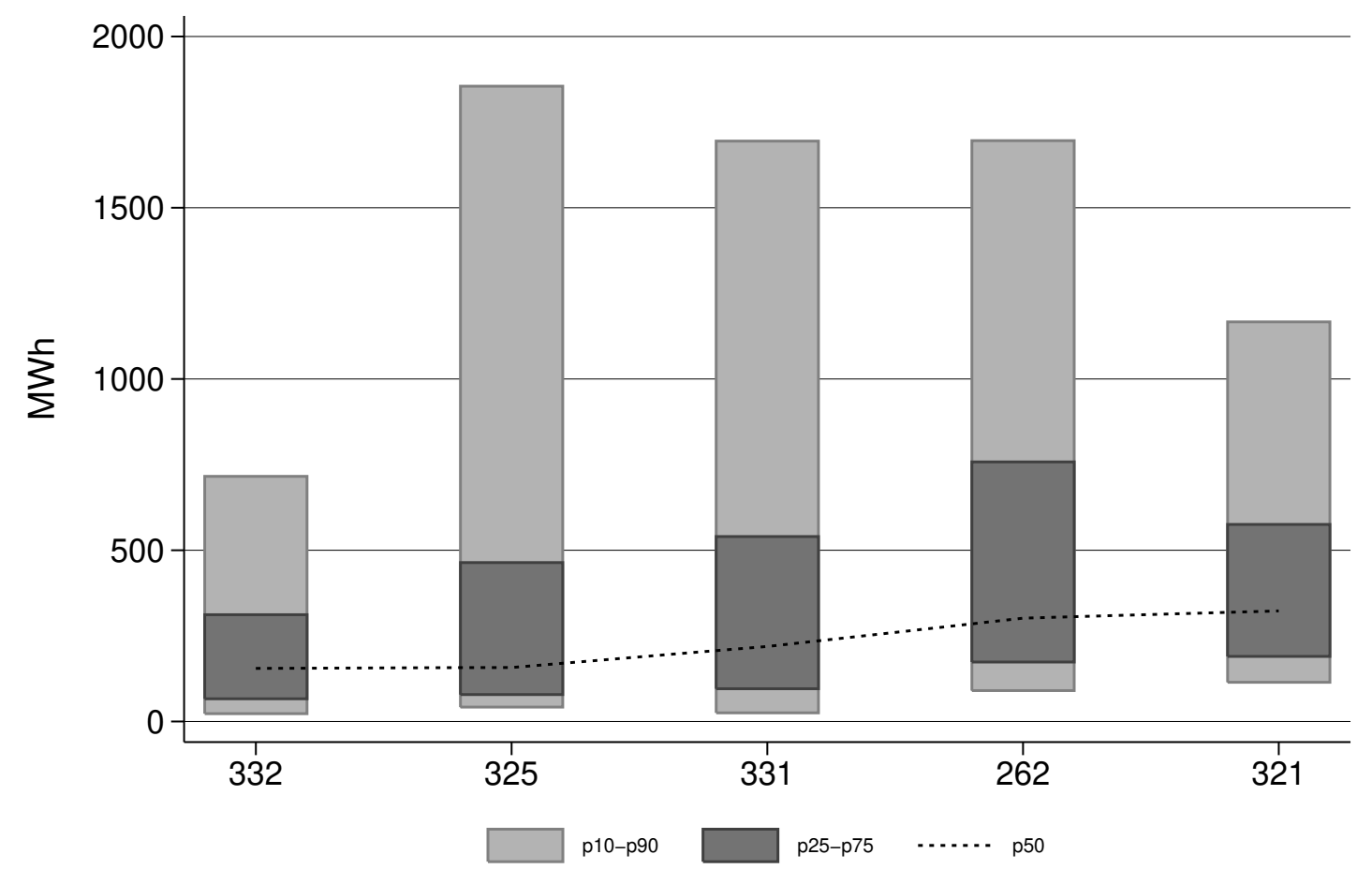

Source: DOI: $10.21242 / 43531.2003 .00 .03 .1 .1 .0$ to $10.21242 / 43531.2014 .00 .03 .1 .1 .0$. Own calculations.

Figure 31: The five sectors with the lowest median energy use in 2014 


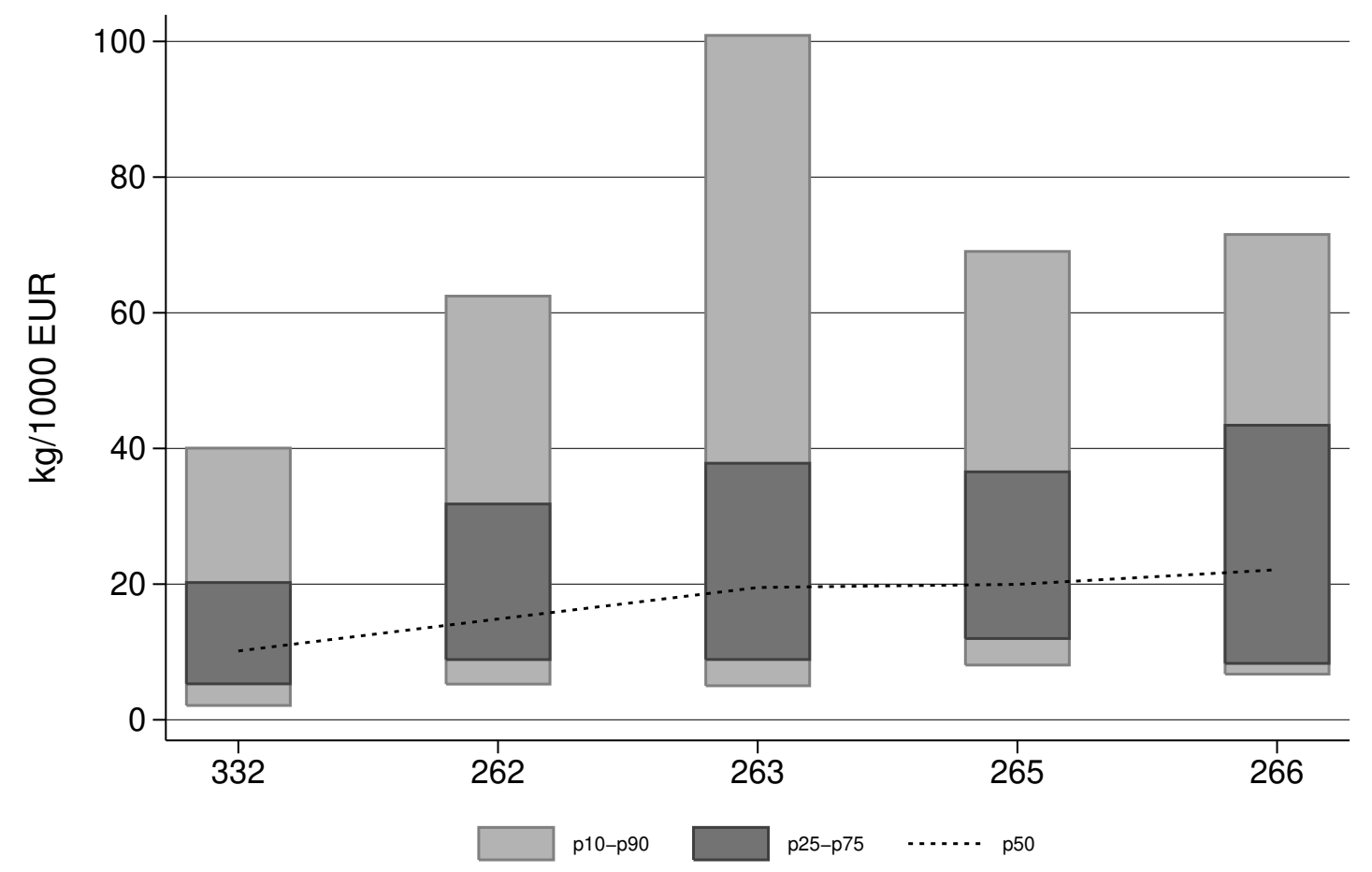

Source: DOI: $10.21242 / 43531.2003 .00 .03 .1 .1 .0$ to $10.21242 / 43531.2014 .00 .03 .1 .1 .0$. and DOI: 10.21242/42111.2003.00.01.1.1.0 to 10.21242/42111.2014.00.01.1.1.0. Own calculations.

Figure 32: The five sectors with the lowest median carbon intensity in 2014 
Table 6: Correlation of sector heterogeneity between selected variables

Source: DOI: 10.21242/43531.2003.00.03.1.1.0 to 10.21242/43531.2014.00.03.1.1.0. and DOI: 10.21242/42111.2003.00.01.1.1.0 to 10.21242/42111.2014.00.01.1.1.0. Own calculations.

\begin{tabular}{|c|c|c|c|c|c|c|c|}
\hline Correlation of heterogeneity $(\mathrm{p} 90-10) / \mathrm{p} 50$ & Total energy use & Energy intensity & Value of output & electricity share & carbon intensity & workforce & payroll \\
\hline Total energy use & 1 & & & & & & \\
\hline Energy intensity & 0.45 & 1 & & & & & \\
\hline Value of output & 0.36 & 0.12 & 1 & & & & \\
\hline electricity share & 0.15 & 0.16 & -0.01 & 1 & & & \\
\hline carbon intensity & 0.40 & 0.96 & 0.13 & 0.12 & 1 & & \\
\hline workforce & 0.13 & -0.00 & 0.85 & 0.13 & 0.03 & 1 & \\
\hline payroll & 0.12 & 0.01 & 0.88 & 0.07 & 0.04 & 0.98 & 1 \\
\hline
\end{tabular}




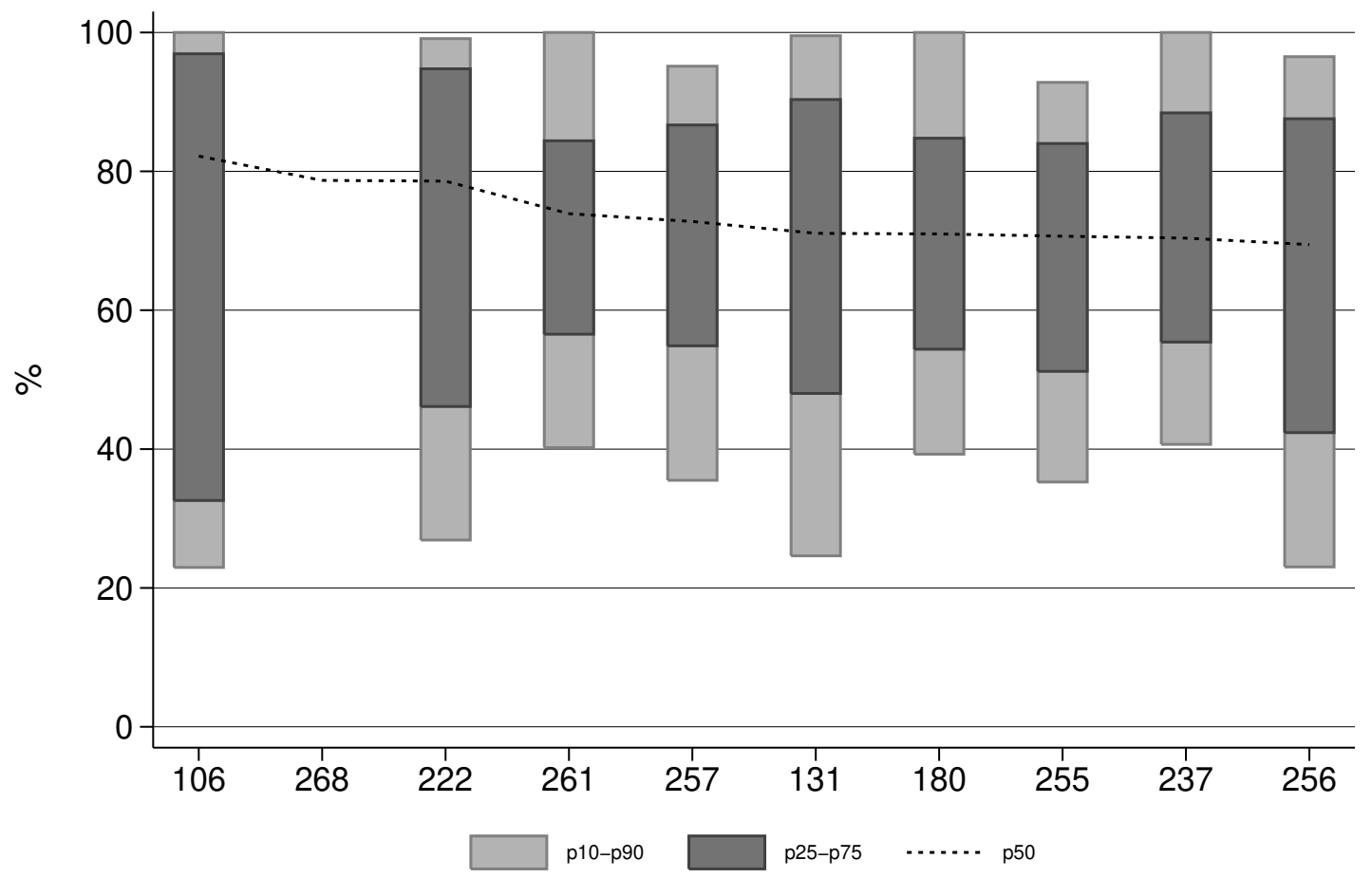

Source: DOI: $10.21242 / 43531.2003 .00 .03 .1 .1 .0$ to $10.21242 / 43531.2014 .00 .03 .1 .1 .0$. Own calculations. For "Manufacture of magnetic and optical media" (268), confidentiality allows only to depict the median.

Figure 33: The ten sectors with the highest median electricity share in their 2014 energy $\operatorname{mix}$ 


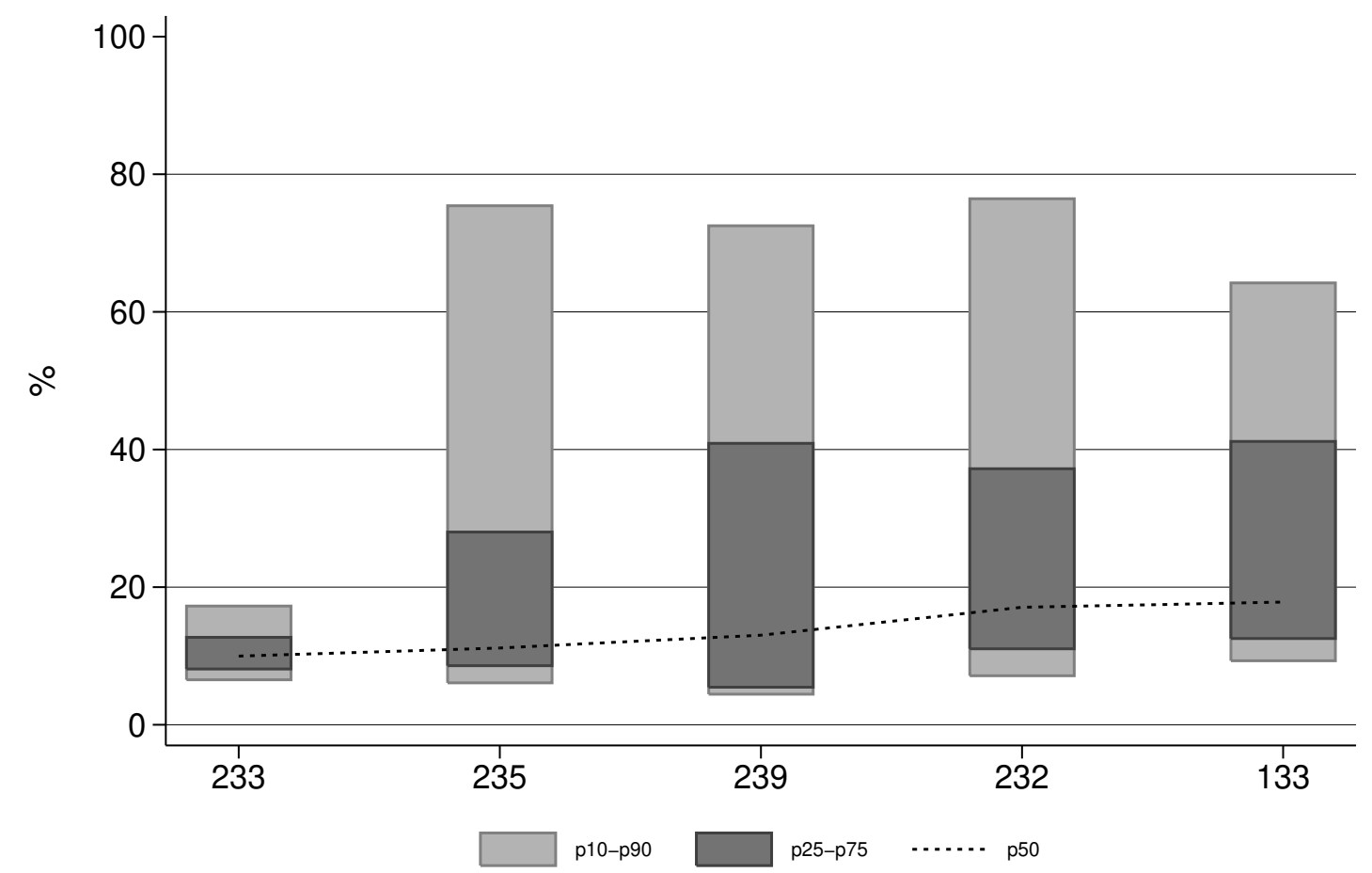

Source: DOI: $10.21242 / 43531.2003 .00 .03 .1 .1 .0$ to $10.21242 / 43531.2014 .00 .03 .1 .1 .0$. and DOI: 10.21242/42111.2003.00.01.1.1.0 to 10.21242/42111.2014.00.01.1.1.0.Own calculations. Note that sector "manufacture of coke" (191) is among the bottom five sectors with respect to the electricity share in the energy mix, but cannot be shown for confidentiality reasons.

Figure 34: The five sectors with the lowest median electricity share in their 2014 energy $\operatorname{mix}$ 


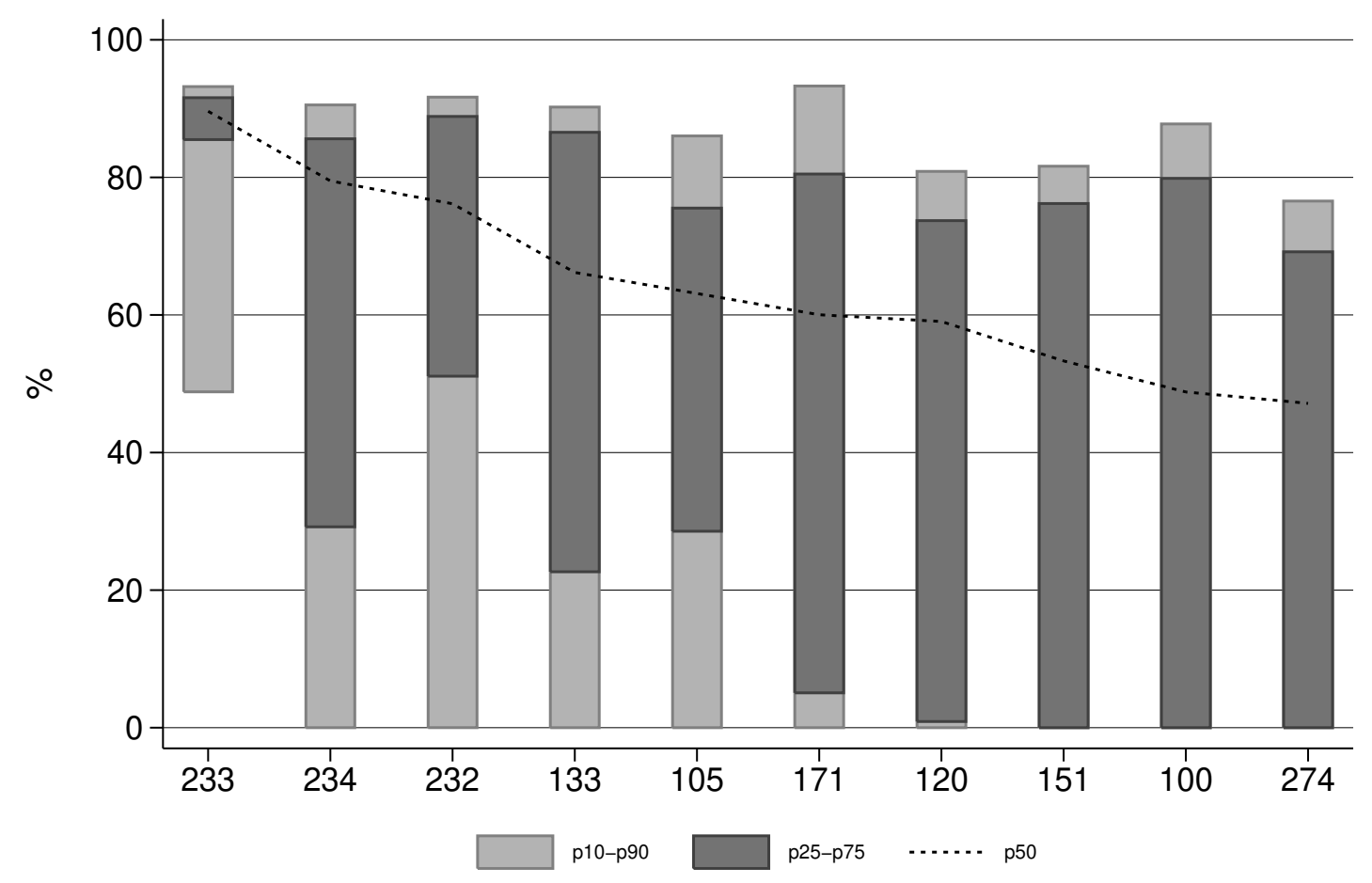

Source: DOI: 10.21242/43531.2003.00.03.1.1.0 to 10.21242/43531.2014.00.03.1.1.0. Own calculations.

Figure 35: The ten sectors with the highest median natural gas share in their 2014 energy $\operatorname{mix}$

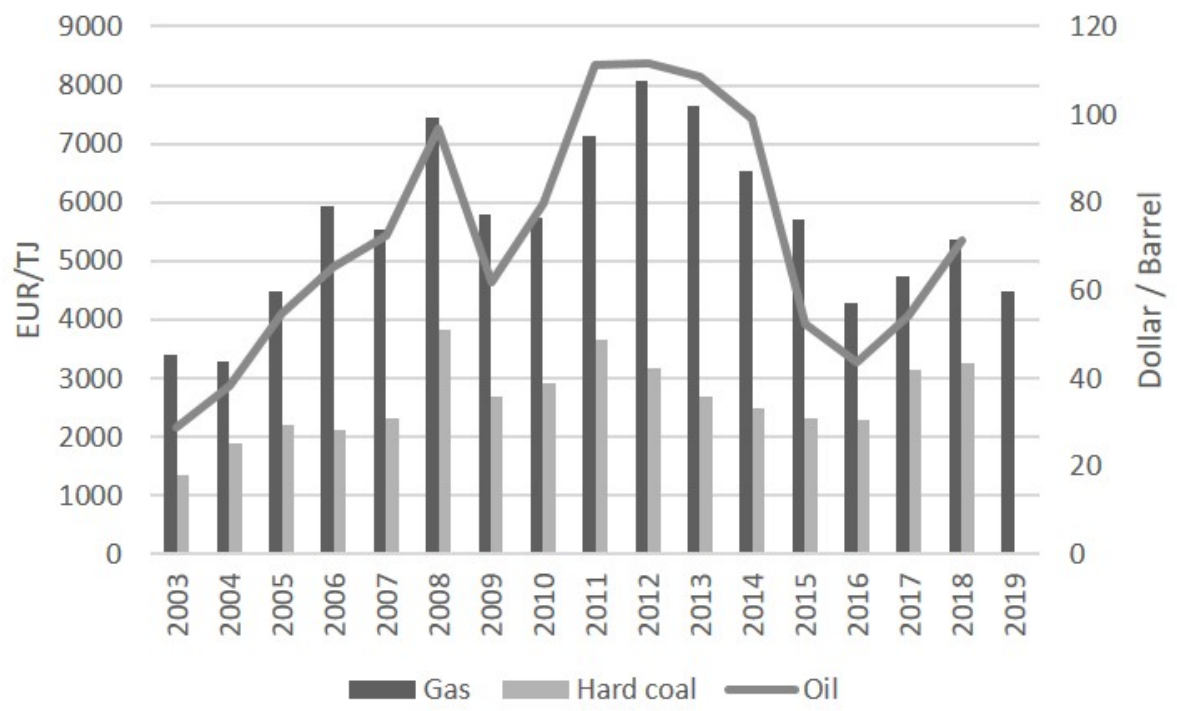

Fuel prices for gas, hard coal and oil from 2003 until 2018. The prices on gas and hard coal come from the website of the Federal Office for Economic Affairs and Export Control (BAFA). The prices for oil come from the US Energy Information Administration (EIA) website.

Figure 36: Fuel prices for gas, hard coal and oil 

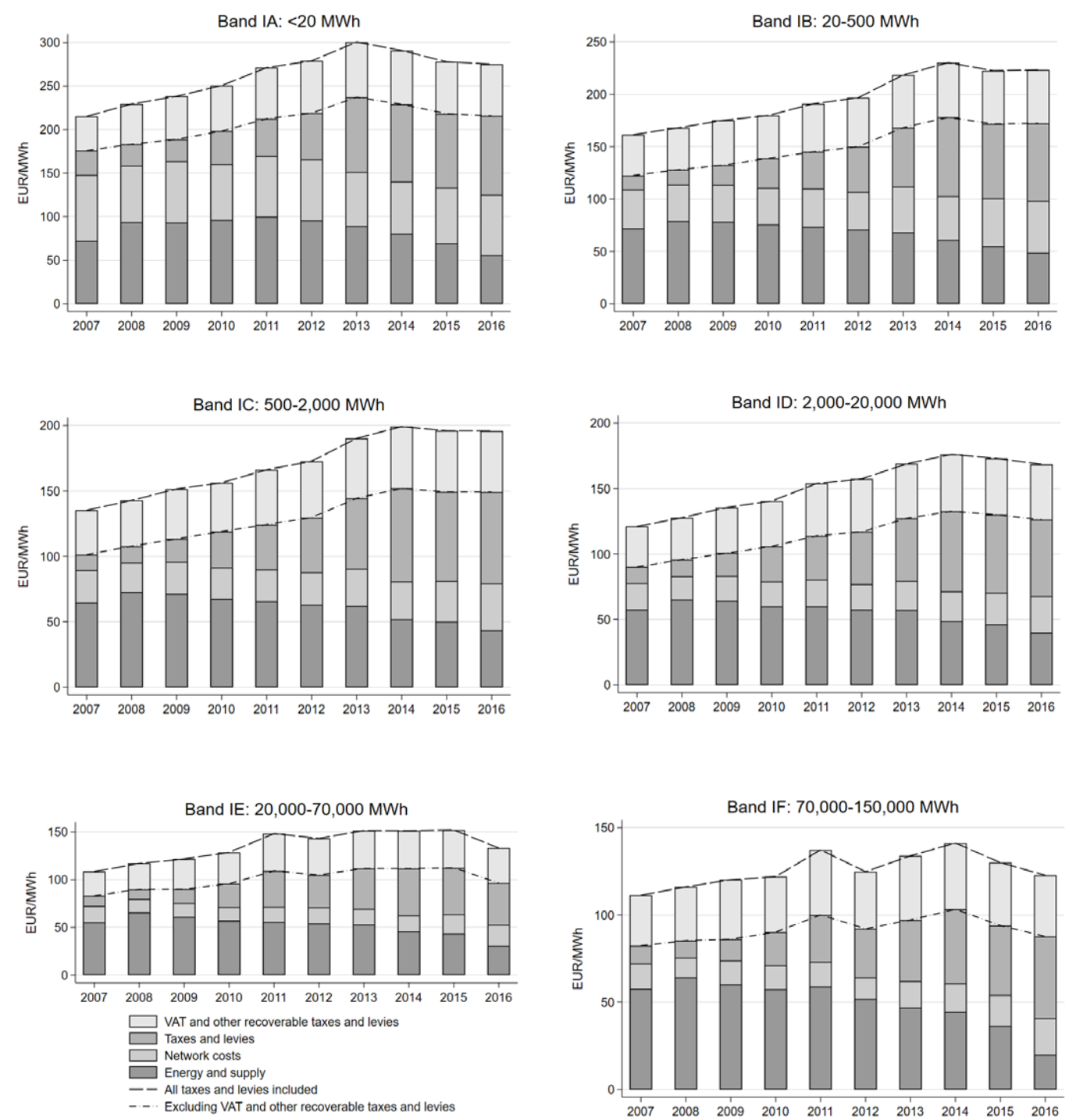

Source: Eurostat time series nrg_pc_205 and nrg_pc_205_c.

Figure 37: The development of electricity prices for different consumption bands 
Download ZEW Discussion Papers from our ftp server:

http://ftp.zew.de/pub/zew-docs/dp/

or see:

https://www.ssrn.com/link/ZEW-Ctr-Euro-Econ-Research.html

https://ideas.repec.org/s/zbw/zewdip.html

$$
\text { // }
$$

IMPRINT

ZEW - Leibniz-Zentrum für Europäische Wirtschaftsforschung GmbH Mannheim

ZEW - Leibniz Centre for European

Economic Research

L 7,1 68161 Mannheim · Germany

Phone +49621 1235-01

info@zew.de·zew.de

Discussion Papers are intended to make results of ZEW research promptly available to other economists in order to encourage discussion and suggestions for revisions. The authors are solely responsible for the contents which do not necessarily represent the opinion of the ZEW. 